\title{
دور منظومة التعليم العالي في اعادة بناء النظام المحاسبي الموحد \\ وفق معاير المحاسبة والإيلاغ الملالي الدولية IAS/IFRS \\ دراسة استطلاعية تحليلية لآراء عينة من أساتذة الجامعات والعاملين في عدد من المؤسسات الحكومية \\ د. موفق عبد الحسين محم \\ أستاذ \\ المحاسب القانوني

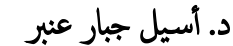

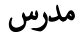 \\ ديوان الرقابة المالية الإتحادي \\ بشير يوسف اسماعيل \\ مدرس مساعد

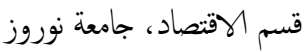 \\ اقليم كردستان العراق تجاق نوروز
}

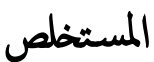

إستهدف البحث تحليل دور أساتذة الجامعات والمؤسسات التعلمية في توفير محاسبين مؤهلين لإعادة بناء النظام المحاسبي الموحد وفق معايير المحاسبة والإبلاغ المالمي الدولية

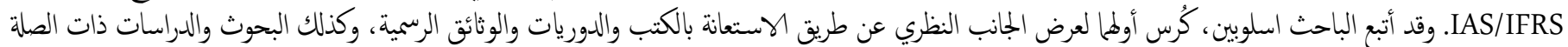

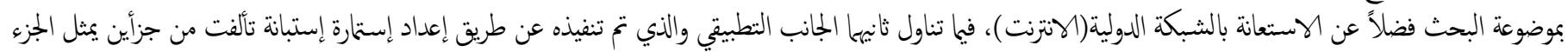

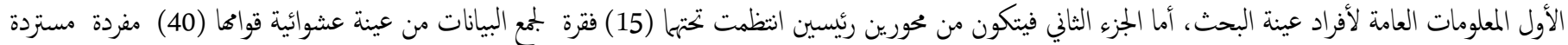

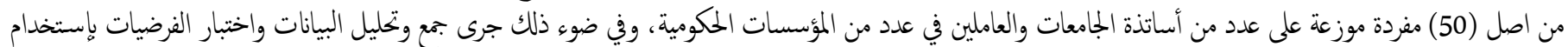

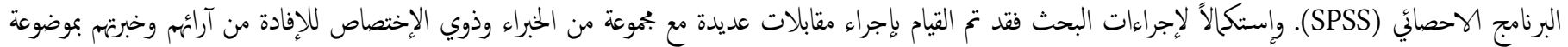

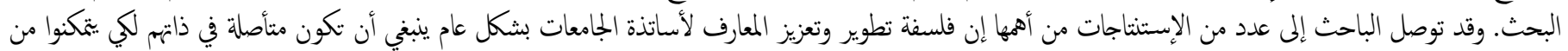

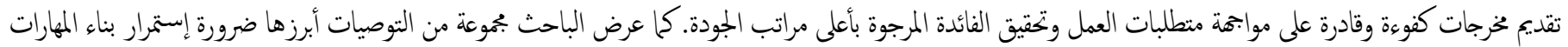

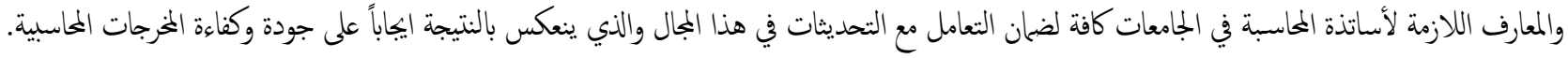
الكلمات الدالة : منظومة التعليم العالي، النظام المحاسبي الموحد، معايير المحاسبة والإبلاغ المالي الدولية.

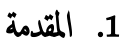

فإن ذلك يجتاج لتهيئة عدد كير من الختصين والأكاديمين وتأهيلهم لهذه النظم المحاسبية الجديدة لبناء موارد بشرية محاسبية كفوءة تعمل على إنجاح هذه المهمة. على هدي ما سبق، ولتحقيق الأهداف التي انطلق منها البحث فقد قُسم على أربعة محاور تناول اولها المنهجية العلمية للبحث وبعض الدراسات السابقة، في حين ناقش ثنيها الجانب النظري للبحث، اما ثاثها فقد خصص لبيان الجانب التطبيقي عن طريق إستطلاع وتحليل النتاجُج وفق إستبيان مُعد لغرض البحث، وجاء رابعها لعرض الإستنتاجات والتوصيات لحل مشكلة البحث بأبعادها كافة، فضلاً عن إثبات الفرضيات التي انطلق منها البحث.

1. 1 مشكلة البحث Research Problem تتلخص مشكة البحث في إفتقار عدد من أساتذة الجامعات للمؤهلات اللازمة لتكوين وتهيئة موارد بشرية محاسبية ومنية قادرة على موابحة المعطيات الجديدة القائمة على التغير في العادات والممارسات المحاسبية نتيجةً لإعادة هيكلة النظام المحاسبي الموحد وفق معايير المحاسبة والإبلاغ الملالي الدولية IAS/IFRS ، مما يؤدي بالنتيجة إلى عدم تحقيق النظام
في وقتنا الراهن ونتيجةً للمستجدات التي أفرزتها التطورات التي تلف عصرنا من كل جانب، تتعالى الأصوات لإعادة النظر بمحتوى النظم المحاسبية المعتمدة في البيئات كافة) ومنها البيئة العراقية) لتضم بين طياتها معايير المحاسبة والإبلاغ الملالي الدولية IAS/IFRS وبما يكنها من تضييق جوة الاختلاف بين القواعد والممارسات المحاسبية، وتحسين قابلية القوائم المالية للمقارنة، فضلاً عن جعلها أكثر قرباً وفهاً لمتطلبات السوق العالمية، مع الإفادة منها في إيجاد حلول للمشكلات المحاسبية التي توابهنا من كل صوب. ولكي يتحقق الدور المطلوب بأعلى مراتب الإنسجام والشمول، لقد تعرض الاقتصاد العالمي للعديد من الأزمات، فسب احصاءات صندوق النقد الدولي خلال الفترة 1970- 2010 تعرض اكثر من ثلثي الدول الاعضاء إلى ازمات

المجلة الاكاديمية لجامعة نوروز, الجملد 8, العدد 1 (2019)

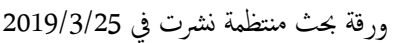

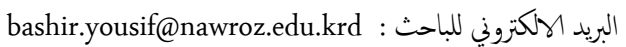
حقوق الطبع والنشر (؟) 2017 أسماء المؤلفين. هذه مقالة الوصول اليها مفتوح موزعة تحت رخصة

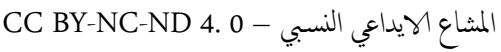


ب. المنهج التهليلي : عن طريق القيام بدراسة استطلاعية تحليلية لآراء عينة من أساتذة الجامعات والعاملين في عدد من المؤسسات الحكومية، عن طريق إعداد إستمارة إستبانة إحصائية وزعت على عينة قواها(50) مفردة تم إسترداد ما نسبته(80\%) منها(أي ما يعادل (40) إستارة)، كما تم إستخدام الأسلوب العشوائي في إختيار هذه العينة، وفي ضوء ذلك جرى جمع وتحليل البيانات واختبار الفرضيات بإستخدام برجية SPSS (Statistical Package for Social Sciences) إلى النتائُ.

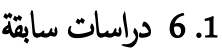
حظيت الأدبيات المحاسبية بالعديد من الدراسات التي تناولت موضوعة تكييف النظام المحاسبي الموحد وفق معايير المحاسبة والإبلاغ المالي الدولية IAS/IFRS، ومن بين أهم

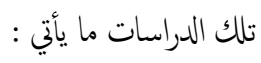
1. دراسة قدوري(2017) : "معايير المحاسبة الدولية وأثرها على اصلاح النظام المحاسبي في اقتصاد العراق" : بينت هذه الدراسة ان تبني هذه المعايير ، سوف يحقق مبدأ التوافق بين النظم المحاسبية والتقارير المالية المتعددة المعمول بها في العراق، والتي تنظم أمورها مصادر مختلفة، كالقانون التجاري الضريبي، قانون الميزانية العامة للدولة، قانون أصول الحماسبات العامة للدوائر والمؤسسات في القطاع العام والجمعيات، وقوانين وحدات إدارة الأعمال في القطاع الخاص، وغيرها. وقد خلصت الدراسة إلى عدد من

$$
\text { النقاط أهمها : }
$$

أ. اصلاح النظام الحماسبي في العراق، بجيث يرتقي الى مستوى القياسي العلمي، مما يعود ذلك بفوائد كيرة على توثيق المعاملات التجارية الداخلية للشركات الوطنية والاجنبية او الثركات العالمية المشتركة.

ب. ضرورة التأكيد على تدريس مادة المعايير المحاسبية الدولية في كليات الاقتصاد وإدارة الأعمال، وكتابة البحوث والدراسات من قبل الأكاديميين والمعنيين بشؤون تطوير النظام المحاسبي في العراق، بجيث تصبح هذه البحوث مرشدا لوضع استراتيجية للجمعيات المهنية الوطنية والجهات الحكومية الخاصة بتطوير واقع هنة المحاسبة ومقوماتها المهنية، ومنها معايير المحاسبة الدولية والمراجعة على المستوين النظري والتطبيقي. 2. دراسة علاوي وآخرون(2013) : "النظام المحاسبي الموحد ومتطلبات التوافق مع المعايير المحاسبية الدولية" : استهدفت الدراسة تحليل ودراسة محاولات تطوير النظام المحاسبي الموحد في العراق بإتجاه تحقيق التوافق والإنسجام مع متطلبات معايير المحاسبة
المحاسبي للنتائج المرجوة من تطبيقه باعتباره المنتج للمعلومات المحاسبية التي تمثل المؤشر

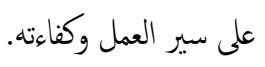

\section{2 أهداف البحث Research Objectives}

$$
\text { يسعى البحث إلى تحقيق الأهداف الآتية : }
$$

أ. النعرف على منظومة التعليم العالي، مع توضيح الإطار العام للنظام الحماسبي الموحد. ب. عرض خلفية نظرية عن معايير المحاسبة والإبلاغ المالي الدولية IAS/IFRS. ت. إجراء دراسة إستطلاعية تحليلية لآراء عينة من أساتذة المحاسبة في عدد من الجامعات، وعرض وتحليل الإجابات عن طريق إستبانة مُعدة لهذا الغرض، مع مناقشة ما تسفر عنه الدراسة من نتاجُج.

\section{Research Significance 3 أهمية البحث}

تنبع أهمية البحث من إيضاح الدور الذي يقوم به أساتذة الجامعات والمؤسسات التعلمية في تطوير وتحسين التأهيل المحاسبي للأفراد لموابجة متطلبات أعادة بناء النظام المحاسبي الموحد وفق معايير المحاسبة والإبلاغ المالي الدولية IAS/IFRS ، وما له من آثار متوقعة وحيوية تسهم في تشكيل بنية الاقتصاد الوطني، كما تتجسد أهمية البحث كذلك من سعيه لإثراء المكتبة العلمية والمهنية بموضوعة تضاف للبحوث والدراسات التي تناولتها من

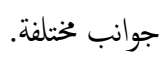

\section{4 فرضيات البحث Research Hypothesis}

$$
\text { يقوم البحث على فرضيتين رئيستين مفادها : }
$$

أ. إن وجود كفاءات تعلمية قادرة على تعزيز معارف المحاسبين بضمون النظام المحاسبي الموحد المعاد بناءه وفق معايير المحاسبة والإبلاغ المالي الدولية IAS/IFRS يؤدي إلى إعداد كفاءات محاسبية مؤهلة للنطبيق بأعلى مراتب الفاعلية والجودة. ب. يوجد دور ذو دلالة إحصائية عند مستوى معنوية(0. 05) لوجود مؤهلات لأساتذة الجامعات وتطوير المخرجات المحاسبية في مجال تطبيق النظام المحاسبي الموحد

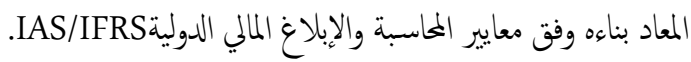

\section{5}

أ. المنهج الوصفي : إذ تم الإعتاد في الحصول على البيانات المطلوبة لمناقشة مشكلة البحث وإثبات ما إنطلق به من فرضيات على ما متوافر من كتب وبجوث ودوريات(عربية وأجنبية) في مكتبة الديوان والمكتبات العامة الأخرى، فضلاً عن البحوث والدراسات المنشورة على الشبكة الدولية(الإنترنت). 


\section{7 ( 7 موضع الدراسة الحالية من الدراسات ذات العلاقة} اختلفت الدراسات السابقة في رؤيتها ومعالجاتها التي يككن تلخيصها في النقاط الآتية : 1. إن جميع هذه الدراسات ركزت على ضرورة تطوير النظام المحاسبي الموحد بشكل يتناغ مع متطلبات معايير المحاسبة الدولية، بما يجعله أكثر قدره على توفير المعلومات

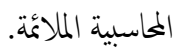
2. المحاسبة والإبلاغ المالي الدولية IAS/IFRS علمياً ومهنياً، ولا كيفية وضع إستراتيجية مدروسة لإنجاح متطلبات تكييف النظام المحاسبي الموحد وفقها في المستقبل القريب. اما الدراسة الحالية فتنفرد بأنها تبين دور منظومة التعليم العالي في إعادة بناء النظام المحاسبي الموحد وفق معايير المحاسبة والإبلاغ المالي الدولية IAS/IFRS، إذ بات من الضروري الإلنفات إلى هذه المنظومة برأي الباحثين لما لها من دور واضح وملموس في تحقيق قدر لا يُستهان به من التقدم في عملية إعادة البناء وفق معايير المحاسبة والإبلاغ المالي الدولية IAS/IFRS، وهذا ما يحاول البحث تغطيته عبر محاوره.

2. المحور الاول : النظام المحاسبي الموحد ودور منظومة التعليم في تكييفه وفق IAS/IFRS 2.1 منظومة التعليم العالي وماهيتها يُعد التعليم ركناً أساساً ومحوراً حماً من محاور الإنتاج المعرفي والعلمي للمخرجات التعليمية التي تخدم الجمتع وترفده بالملاكات المؤهلة لقيادة عملية التطوير وتفعيلها (عارف، 2015 : 194)، وقد أضحى التعليم العالي الأداة الفاعاة في تطوير المجتمعات والنهوض بها مقارنة بما كان عليه الوضع في العقود القليلة الماضية وذلك لما تتطلبه التقانات الحديثة من مستوى علمي وبكثي متميز، كما أصبح يشكل أيضاً مورداً إقتصادياً هاماً لا يُستهان به في دع الإقتصاد الوطني للدولة(طرابلسية، 2011 : 27)، والابنكار النكنولوجي وخلق Higher المعرفة(الجمالي والنوايسة، 2012 : 778). وقد عرَّف التعليم العالي Education بأنه "بموعة المنافع التي تقدما المؤسسات التعليمية التي تستقطب الخخرجات المميزة في التعليم الثانوي وتختص بتنميتهم وتطوير معارفهم وماراتهم لمسايرة مختلف التغيرات التي تحدث في البيئة الخارجية ومحاولة التكيف معها، ومن ثم تلبية حاجات ورغبات الأطراف المستفيدة من خدماتهم وتحقيق رضاهم"، (رقاد، 2014 : 24)، كما عرَّف بأنه "كل أثماط التعليم وأنواعه التي تلي المرحلة الثانوية، وتقدمه الجامعات والكليات الجامعية والكليات المتوسطة والمعاهد والأكادييات للحصول على شهادات
الدولية في إطار تطوير النظام المحاسبي الموحد وتطبيقاته المختلفة في مجال المفاهيم وعمليات القياس والإفصاح المحاسبي وبما يخدم تشجيع جذب الإستثمارات الأجنبية وتخقيق التوافق النظم المحاسبية على المستوى الدولي. وقد توصلت الدراسة إلى مجموعة إستنتاجات أهها أ. يعود تبني النظام المحاسبي الموحد والمدخل المعتمد في عملية التوحيد في جزء كير منها إلى إختلاف طبيعة ونوع التنظيم العام لمهنة المحاسبة المعتمد في الدولة. ب. تمثنل الأهداف المحاسبية للنظام المحاسبي الموحد بشكل عام على المستوى التطبيقي بتوفير المعلومات المحاسبية المفيدة لأغراض التخطيط الإقتصادي المركزي للدولة إلى جانب المتطلبات الضريبية والأطر اف الأخر على اعتبار ان تلك الأطراف هي أبرز الأطراف الممولة للنشاطات الإقتصادية وهو ما يخالف الأهداف المطلوبة من جراءوضع وتطبيق معايير المحاسبة الدولية.كما عرضت الدراسة عدة توصيات منها ضرورة تشكيل لجان متخصصة تتولى دراسة كل معيار دولي من أجل تحديد درجة إنسجامه والأهداف الإقتادية والإجتاعية للبيئة العراقية وإحلال التطبيقات الملائمة وأبعادها المختلفة، مع ضرورة إدراك الحاجة للنظام المحاسبي الموحد في البيئة العراقية لما يوفره من إمكانيات كمة لرفع كفاءة العمل المحاسبي في العراق. 3. دراسة أحمد ومحود (2009) : "إمكانية تطوير النظام المحاسبي الموحد المطبق في المصارف العراقية في ضوء معايير الحماسبة الدولية" : رامت هذه الدراسة زيادة فاعلية النظام المحاسبي الموحد المطبق في المصارف العراقية من خلال محاولة استخدام معايير المحاسبة الدولية ذات العلاقة، وبما يجعل من هذا النظام أكثر قدرة على توفير المعلومات المحاسبية الملائمة وذات موثوقية لمستخدميها. وقد توصلت الدراسة إلى إستنتاجات عدة، منها إن النظام المحاسبي الموحد المصرفي لم يأخذ بمتطلبات الإفصاح عن بيانات التدفق النقدي التي يككن أن تقدم من خلال إعداد قائمة للندفقات النقدية، حيث أن هذه القائمة أصبحت في الوقت الحاضر من القوائم المالية الأساس، كما يخلو النظام المحاسبي الموحد المصرفي من متطلبات الإصاح عن الاطراف ذات العلاقة. أما أهم التوصيات التي جاءت بها هذه الدراسة فقد بينت بأنه أصبح من الضروري إعادة صياغة النظام المحاسبي الموحد المصرفي بعد هذا التاريخ من التطبيق، وفي ضوء المعطيات الاقتصادية المستجدة والمتغيرة، وبالشكل الذي يلائم معايير المحاسبة الدولية- ذات العلاقة - التي لاقت وتلاقي يوماً بعد يوم الرواج على المستويات الحملية والإقليمة والدولية، مستنداً

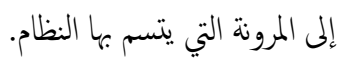


المنشآت الصناعية الإنتاجية التابعة لها، وإعتباراً من السنة المالية 1973 قامت المصاح النفطية بتطبيق دليل موحد للحسابات المالية يتناسب وطبيعة نشاط هذه المصالح، ثم حذت وزارات أخرى حذو وزارة الصناعة والمعادن بعد أن قامت هذه الوزارات بإعداد نظام محاسبي خاص بكل منها وتعميم تطبيقه على المنشآت التابعة لها (النظام المحاسبي الموحد، 1985 : 8). وقد أدى إختلاف النظم المحاسبية التي تم تطبيقها(سبب اعدادها لخصوصيات منشآت الوزارات) إلى ظهور إختلافات في المسميات والمعالجات القيدية والإجراءات الواردة في كل منها، فضلاً عن الإجتهادات سواءً في الاعداد أو التطبيق، لذا فقد ظهرت الحاجة إلى إعداد نظام محاسبي موحد يؤمن إحتياجات الإدارة وأبهزة التخطيط والرقابة، وعليه فقد أصدر مجلس قيادة الثورة(المنحل) قراره المرج(380) في1979/4/5 الذي يقضي بتشكيل لجنة بإسم(اللجنة الرئيسة للنظام المحاسبي الموحد) ضمت في عضويتها مثلين عن ديوان الرقابة المالية الإتحادي والمركز القوي للإستشارات والتطوير الإداري ووزارة المالية وعدد من ذوي الخبرة والإختصاص في هذا المجال، ليتم بعد ذلك تشكيل اللجنة الرئيسة عام1980(النظام المحاسبي الموحد، 1985 : 9). ونتيجةً للتطورات التي حصلت وتضمين بعض التثريعات نصوص تقضي بإعتاد معايير المحاسبة الدولية، ومضي(25) عاماً على إصدار النظام المحاسبي الموحد سنة1985، ليلبي إحتياجات المرحلة الراهنة، لذا فقد أثمرت الجهود على إصدار النظام بصيغته الجديدة متضمنا عثر فصول لا تختلف عن سابتها في الإصدار الأول بإستثناء عدد من التعديلات لبعض من المعالجات القيدية، مع إضافة بعض الحسابات لسنة2011(ممدان وفرحان، 2014 : 5). والشكل(1) في الأدنى يعرض محتويات النظام المحاسبي الموحد وفق إصدار سنة2011، وعلى النحو الآتي :
الدبلوم أو الشهادة الجامعية أو الدرجات الجامعية لما فوق الشهادة الجامعية"(العيبي، بلا سنة نشر : 4)، وعرَف كذلك بأنه "عملية توفير خدمة التعليم لعدد كير من الأفراد يتم تقسيهم على مجموعات متعددة من خلال مجموعة من الأفراد المتخصصين(خبراء، مدرسين) بإستعال وسائل وادوات مختلفة في طبيعتها في مكان ما وفي موقع جغرافي معين يلتتي فيه الجميع في زمن ما يتم تحديده وجدولتهِ سابقًا"، (عبد الرمن وآخرون، بلا سنة نشر : 4). ويرى بعضهم(عنبر والعمار) بأن التعليم العالي يتتع بأهمية قصوى لكونه يمثل الأداة الرئيسة والفاعلة في تغذية سوق العمل باليد العاملة، من خلال زج مخرجاته في قطاعات الدولة كافة لتنفيذ الأعال الموكولة لها والذي ينعكس بالنتيجة الهائية على خدمة النهة والتنمية الإقتصادية في البلاد(عنبر والعمار، 2015 : 10-11). وعلى الرغز من السعي المستمر للمدول المتقدمة في الإرتقاء بالنظام النعليمي من خلال توفير الإمكانات اللازمة لمساعدة المؤسسات التعلمية للقيام بدورها التعليمي على أكمل هرب وجه، إلا أن هنالك بعض الإشكلات والعبـات التي تواجه النظام التعليمي، فنتعكس سلباً على سير العملية التعلمية، وبالتالي تؤثر على التنمية المنشودة في جميع مجالات ونواحي الجمتعع ومن هذه التحديات : الأعداد المتزايدة من الطلبة، ومناهج التعليم، وتدريب المعلمين وتأهيلهم، وسوق العمل ومخرجات التعليم، والمباني والتجهيزات المدرسية(الحولي وشلدان، 2012 : 680). من جانب آخر فإن ازدياد أعداد المتعلمين يؤدي إلى تطلعهم أو في الأقل تزايد الفضول المعرفي للبعض منهم وسعهم لإكتساب المزيد من المعرفة العامة أو المتخصصة أو لإكتساب محارات وحرف، كل ذلك يُنشئ حاجة للتعليم العالي ويدفع إلى تنويعه، وقد تبرز الحاجة إلى تعليم من البناء الفوقي للمجتمع، مثل حاجة السلطات إلى إداريين وحرفيين وأصحاب محارات، مما يؤدي إلى الدعوة إلى تعليم عام وإستحداثه أو توسيعه وتشجيعه، ومن ثخ قيام تعليم عال وتنميته وتطويره، . . • وهكذا(عبد الغفور والحجاج، 2014 : 25). 2.2 يُمثل النظام المحاسبي الموحد بمجوعة من الإجراءات والعمليات الخاصة بتسجيل البيانات المحاسبية الماصة على مستوى الوحدة الإقتصادية أو على المستوى القومي بهدف إعداد الموازنات التخطيطية والحسابات الخنامية في إطار محدد من الأسس والقواعد والمبادئ والمصطلحات وذلك لخدمة أهداف محددة. وقد طبق النظام في جمهورية العراق من قبل وزارة التجارة منذ سنة1971 ثم طبق بعد ذلك في المؤسسة العامة لصناعات الغزل والنسيج والمنشآت التابعة لها إعتباراً من السنة المالية1972، إذ جرى تعميمه على جميع 


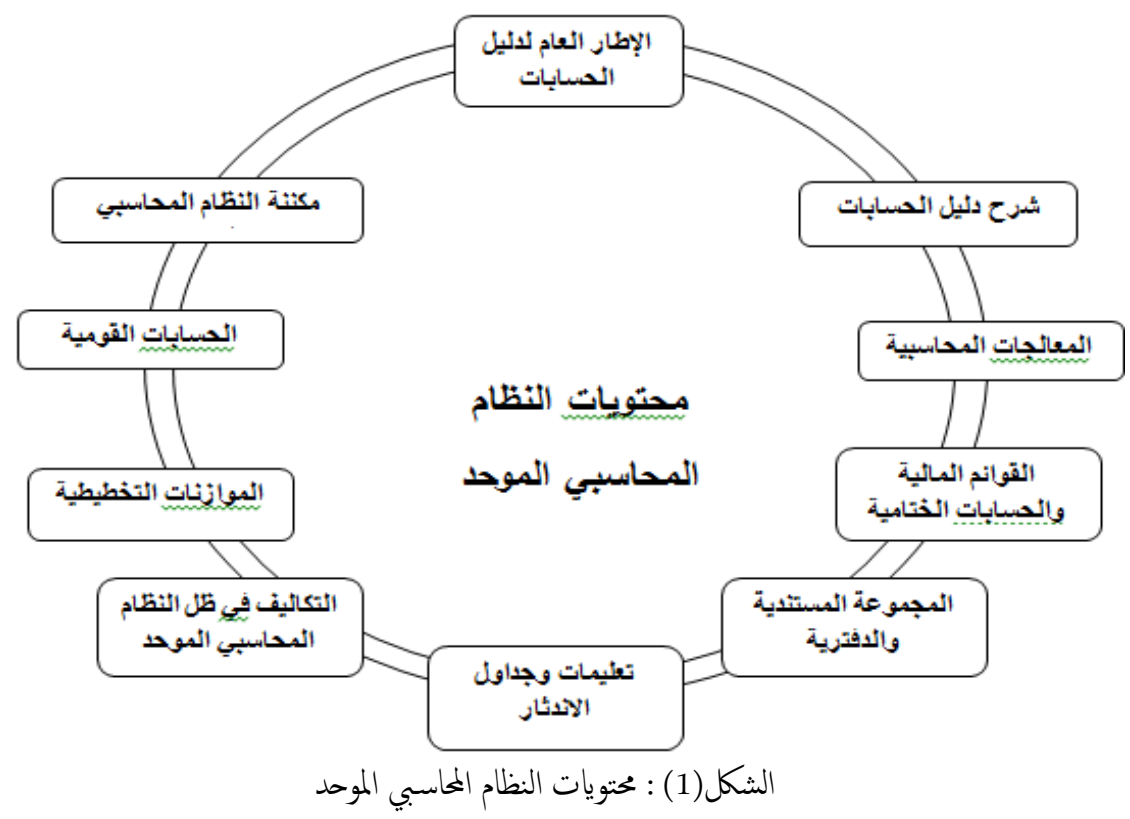

المصدر : (حمدان وفرحان، 2014 : 5)

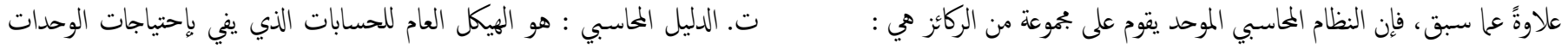
أ. المجموعة المستندية : التي تُعد أحد مقومات النظام المحاسبي الموحد والتي من خلالها الإقتصادية اللازمة كافة لتطبيق النظام المحاسبي الموحد، وقد أنبعت طريقة التزميز يجري تسجيل العمليات الخاصة بنشاط الوحدة، ولها أهمية بالغة لكونها تُعد دليل إثبات العشري للحسابات، إذ أعطي لكل حساب من حسابات الدليل رقٌ خاص به يختلف

موضوعي للتحقق من صحة العمليات، وتتوقف علها صحة النتائج المحاسبية، وبدونها تقفد عن بقية أنواع الحسابات، ويتضمن هذا الدليل ثلاثة مجاميع من الحسابات وهي : السجلات موثوقيتها، وتتضمن المستندات(وصل القبض، مستندات الصرف، الجمموعة الأولى : حسابات المركز المالي(الموجودات والمطلوبات : وتتضمن حسابين مستندات القيد، قوائم البيع(النقدي والآجل)، مستند صرف النثرية وكثف مصروفات إجاليين ها(الموجودات والمطلوبات)، إذ أعطي للحساب الأول رقّ[1] لأنه حساب إجالي، وبعده يأتي حساب عام يتكون من[-9] مثل حساب الموجودات الثابتة النثرية). حساب عام[11]، وهذا يعني إنه على المستوى الثنائي، ويتفرع منه حسابات مساعدة وتبدأ كذلك من[1-9] على يمين الحساب العام، وهذا يعني إنه على المستوى الثلاثي مثل حساب وسائط نقل وإنتقال[114] وهو حساب مساعد، ويتفرع منه حسابات فرعية تبدأ من[-9] على يمين الحساب المساعد مثل حساب وسائط نقل بالسيارات[1141] وهو على مستوى رباعي والذي بدوره يتفرع إلى حسابات جزئية وتبداً من[1-9] على يمين الحساب الفرعي وذات مستوى خحاسي مثل وسائط نقل الركاب[11411]، وبهدف تطوير النظام وبما يلائم حاجة الوحدات الإقتصادية، فقد تم إضافة مستوى جديد(سداسي) ليتفرع إلى مستوى(الحسابات التهليلية). ب. الدفاتر والسجلات : وتخصص لإثبات وحصر جميع العمليات المالية التي تجري داخل الوحدة الإقتصادية، ويتم التسجيل في تلك الدفاتر من واقع المستندات بإعتبارها مصدر المعلومات والبيانات، وتتضمن هذه المجموعة(دفتر اليومية العامة(المركزي)، اليوميات المساعدة(المقبوضات، المدفوعات، المشتريات، الإيرادات، الصادر المخزني، الإستخدامات)، وينقسم النبويب في دفتر اليومية العامة إلى قسمين رئسين، ها : أولاً : قسم الحقول التنظيمية : ويحتوي على عدة حقول بغرض المساعدة على إستخراج المعلومات وبما يسهل الرجوع اليها(تاريخ المستند، رق المستند، البيان والتفصيل، مبلغ رئل المجموعة الثانية : حسابات النتيجة(المصروفات والإيرادات). ثانياً : قسم حقول الحسابات العامة : ويختوي على عدة حقول تخصص للحسابات العامة المجموعة الثالثة : حسابات مراكز الكلف(النكليف) : وتبدأ من[5-9] وهي : (حساب مراكز الإنتاج، وأعطي له حساب إجالي رقّ[5]، حساب الخدمات الإنتاجية، وأعطي وعلى المستوى الثاني(اساً ورقاً) ولكل من الجانب المدين والدائن عدا الحقل الأخير، فيستعان به لتثبيت الحسابات الأخرى المتبقية والتي عادةً تكون قلية الحركة. 
لل حساب إجالي[6]، حساب الخدمات التسويقية، وأعطي له حساب إجالي رقّ[7]، مراكز الكلف بمثابة حلقة وصل بين الحسابات المالية وحسابات النكليف للوحدة حساب الخدمات الإدارية، وأعطي له حساب إجالي رق[8]، مراكز الخدمات الإقتصادية(النظام المحاسبي الموحد، 2011 : 12- 13، 285-287، 297-298)، الرأسالية، وأعطي له حساب إجالي رةٌ[9])، وتوزع على هذه المراكز (التي تقوم بحصر والشكل(2) في الأدنى يبين تسلسل تبويب الحسابات، وكما يأتي : الوظائف الرئيسة للوحدة الإقتصادية) حسابات الإستخدامات الختلفة، وبذلك تكون

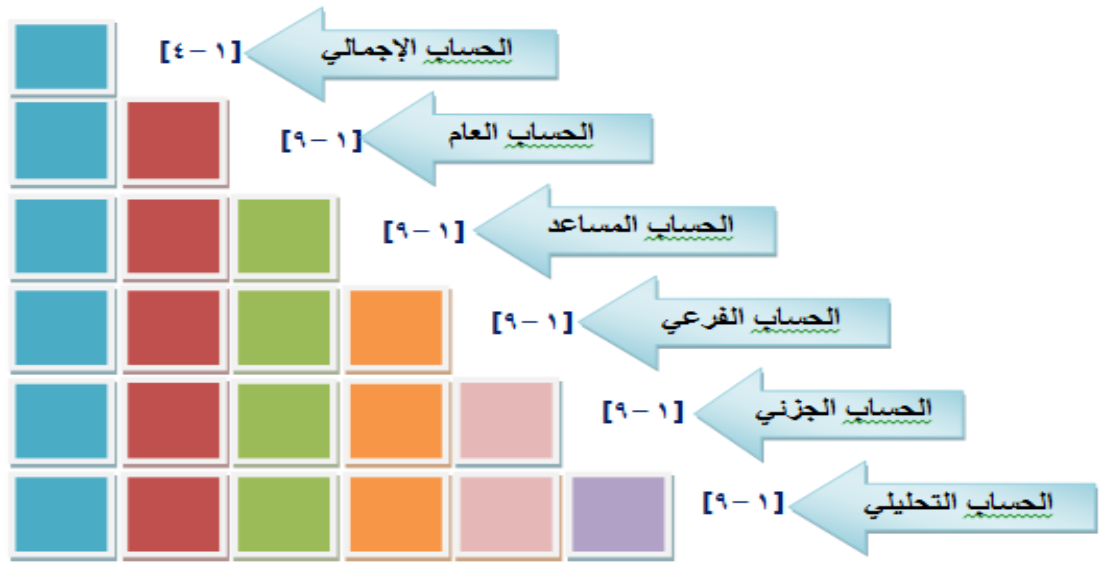

$$
\begin{array}{r}
\text { الشكل(2) : تسلسل تبويب الحسابات } \\
\text { المصدر : اعداد الباحث }
\end{array}
$$

وأسس المعالجات المحاسبية، وتوفير قاعدة واحدة لقراوة القوائم المالية لمختلف الشركات من خختلف البلدان وتزيد الثقة في المعلومات التي تحتوهها لتدارك الإنرافات بإتخاذ

$$
\text { الإجراءات التصحيحية المناسبة في الوقت اللازم. }
$$

وقد أطلقت الأدبيات تعريفات كثيرة عن معايير المحاسبة الدولية، فقد عرَّفت بأنها "بيانات كتابية يصدرها جماز أو هيئة تنظميمة محاسبية رسمية كانت ام حهنية تثناول تنظيم الاسلوب المناسب لتحديد وقياس عرض عنصر محدد من عناصر القوائم المالية للوحدة الاقتصادية وذلك لأغراض تحديد ننائج الأعال وبيانات المركز المالي لتنك الوحدة بدرجة مناسبة من الدقة والموضوعية" (نجم، 24 : 2009)، كما عَّفت بأهها " قواعد لقياس العمليات الإقتصادية والافصاح عن نشاط الوحدة الإقتصادية ومركزها المالي لتوحيد العمل المحاسبي للعمليات والأحداث على المستوى المحلي او الدولي ما يجعل الكثوفات المالية قابلة للمقارنة والفهم من قبل الأطراف ذات العلاقة"، (كندوري، 2012 : 261)، وعرَّفت كذلك من قبل لجنة معايير المحاسبة الدولية( International Accounting بأنها "عبارة عن قواعد إرشادية يستند إلهيا (Standards Committee- IASC المهنيون لدع اجتهادهم واستلهام حكهم المهني، ولكنها لا تلغي الحكم أو الاجتهاد، إنما
2.3 خلفية نظرية عن معايير المحاسبة والإيلاغ الملالي الموليةIAS/IFRS 2.3.1 معاير المحاسبة والإيلاغ الملالي الدولية IAS/IFRS ونشأتها غُرفت المحاسبة منذ ظهورها على أنها المنبع الوحيد والأكيد للمعلومات التي تسهم بشكل رئيس في ترشيد قرارات مستخدميها، وتبوأت هذه المكانة بفضل خصوصيات وسات تطورها الذي كان ملازماً لتطور الشعوب والمجتمعات بالشكل الذي يؤدي إلى تلبية احتياجاتهم من المعلومات على تعددها وتنوعها (سعاد، 2010 : 8). ولقد زادت أهمية المحاسبة في ظل احتياجات عولمة الإقتصاد وعولمة أسواق المال بإعتبارها لغة الأعال والإستثمارات والأداة المترجمة للأحداث الإقتصادية، التي يتجلى هدفها في معالجة وتنظيم المعلومات المالية والإقتصادية على الصعد كافة(المحلية، والوقليمة، والدولية). ونتيجةً لمتطلبات التطورات الإقتصادية عرفت المارسة المحاسبية تغيرات جذرية ملموسة في مختلف أقطاب العالم أدت لعولمة المحاسبة، ومن أجل تقريب وتوحيد هذه الممارسات، جاءت فكرة وضع أسس دولية لمهنة المحاسبة، أدت بعد ذلك تدريياً إلى نشوء ما يعرف بـ(معايير المحاسبة الدولية) International accounting Standard- IAS التي تهدف وبلا جدال إلى إستعال لغة محاسبية موحدة تتجاوز الإختلافات في تطبيق قواعد 
المالية، وتسمح بإجراء المقارنات على عدد من الوحدات الإقتصادية وتقديم الواقع الإقتصادي عن تعاملاتها، أضف إلى توافر مجالاً لغوياً مشتركاً للمحاسبة التي تعالج كل العمليات لإكنال معاييرها أكثر من أي مرجع آخر وتوافقها مع التطورات الإقتصادية بإستمرار، وأخيراً تؤدي إلى تحسين جودة المعلومات التي ينتجها النظام المحاسبي بتوفيرها لمعايير محاسبة دولية موحدة تسمح بإعداد قوائم مالية موحدة للشركات متعددة الجنسية، كما تسهل كمة مصاح الضرائب في مختلف الدول نظراً للنسيق في تطبيق أساليب الإعتراف بالإيرادات والتكاليف(كتوش، 2014 : 273). اما الخصائص الأساس الواجب توافرها في هذه المعايير حتى تحقق الفائدة من وجودها فيمن إيجازها بالآتي (177 : Rogero,1998) و(فهيم وعادل، 2014 : 244) : أولاً: ان تكون مكتوبة بشكل واضح وقابلة للفهم ومباديها قابلة للتطبيق ، وأن تتميز بالمرونة والقابلية على التغيير والتعديل وفق الظروف الاقتصادية والمستجدات التي تطراً في ببئة الاعمال الدولية نتيجةً للبدائل والخيارات التي تحتوها والتي تهدف إلى تسهيل تطبيقها وزيادة درجة قبولها. ثانياً: أن توفر توجيهات للقياس والاعتراف للعملية او الحدث.

ثالثاً: أن تفصح عن الأداء المالي للوحدة الإقتصادية لمستخدي الكثوفات المالية. رابعاً: تقوم على معالجة العمليات المحاسبية من خلال مبادئ محاسبية متطابقة(إطار تصوري) وليس قواعد. خامساً: تعتمد على مقاربة تعكس الواقع الإقتصادي للأحداث على حساب شكلها القانوني. سادساً: تولي أهمية كيرة للملاحق كنصر أساس من عناصر القوائم المالية. سابعاً: تعتمد مبدأ أولوية الميزانية على حساب النتائُ. ثامنأ: تعتمد مفهوم القيمة العادلة للتمكين من التقدير الجيد للوضع الحقيقي للوحدة الإقتصادية. تاسعاً: تعتمد مفهوم القيمة العادلة بهدف معرفة أثر عنصر الزمن في عملية تقييم الموجودات والمطلوبات. عاشراً: تأخذ بعين الإعتبار قياس الخسارة والتناقص في قيمة الموجودات. أحد عشر: تطبيقها يكون بأثر رجعي، أي كما لو كانت المعايبر مطبقة منذ نشأة الوحدة الإقتصادية.
هي وصف مني رفيع المستوى للمارسات المهنية المقبولة قبولاً عاماً، وتهدف إلى تقليل درجة الاختلاف في التعبير أو المارسة في الظروف المتشابة، وتعتمدكإطار عام لرفع نوعية وكفاءة العمل الفني ولتحديد طبيعة وعمق المسؤولية المهنية"، (الراوي، 1995 : 46-45)، وعرَّفت أيضاً بأنها" بمحوعة من الأسس والضوابط والتوجيهات تستهدف رك معالجة موضوعات محاسبية عامة أو خاصة وذلك طبقاً للمبادئ والأعراف المحاسبية المتفق عليها والمقبولة قبولاً عاماً" (عبد الرحن، 1997 : 57)، اما معايير الابلاغ الملالي الدولية فتعني جموعة (International Financial Reporting Standard- IFRS) المعايير الصادرة عن مجلس معايير المحاسبة الدولية International accounting Standard Board- IASB)

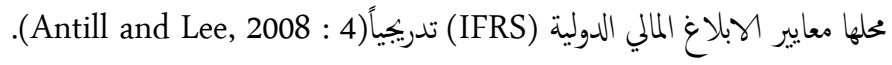
ويكن تلخيص أبرز الاختلافات بين (IAS) و( IFRS ) بالآتي(ياسين، 2017 : 18) أولاً- تشير (IAS) المى معايير المحاسبة الدولية، بينها تشير (IFRS) الى معايير الابلاغ الدولية. ثنانياًتخ اصدار (IAS) للفتزة (1973-2001)، بينا (IFRS) اصدرت اعتباراً من (2001) والى يومنا هذا. ثالثاً -تم اصدار (IAS) من قبل لجنة المعايير المحاسبية الدوليةIASC، بينا (IFRS) من قبل مجلس معايير المحاسبية الدولية ( IASB). رابعاً تُعد (IFRS) متممة للمعايير السابقة، وعند وجود تعارض واختلافات بين مبادئ بعض المعايير فإن (IFRS) تلغي المعيار السابق وتستبدله بمعيار آخر . ويكن القول، إن وجود معايير محاسبية (لكونها مرجع رسمي محاسبي وحيد معترف به دولياً ومطبق في العديد من دول العالم) يعزز من دقة وموثوقية وجودة المعلومات المحاسبية، فضلاً عن اتاحة الشفافية والمصداقية وسهولة القراءة لمجمع المستفيدين، مع وجود ضبط في إرساء الممارسات المحاسبية، والذي يقلل بالنتيجة حالات الغش والتلاعب المحتمة بين طوائف المحاسبين. IAS/IFRSS 2.3.2 أهية وخصائص معايير المحاسبة والإيلاغ الملالي الدولية تكمن أهمية معايير المحاسبة والإبلاغ الملالي الدولية IAS/IFRS وإيجابيات تطبيقها كأساس لإعداد القوائم المالية على الصعيد الدولي، في تمتعها بالقبول الدولي والإعتراف بها عالمياً، علاوةً على أنها تزيد من ثقة المتعاملين في الأسواق المالية الدولية تجاه القوائم 
قبل العديد من دول العالم، مما يسهل بالتالي مقارنة القوائم المالية المعدة بناء عليها لمنشآت

من دول مختلفة.

سادساً: تخفيض كلفة معالجة البيانات المحاسبية : وذلك ايضاً عن طريق توحيد الهسس الخاصة بإعداد القوائم المالية، إذ ان الأسس المختلفة تكلف متخذ القرار بتكليف اضافية لمعالجة هذه القوائم التي يككن الاستغناء عنها عند استعال IAS/IFRS. من جانب آخر فإن تطبيق IAS/IFRS يتعرض لمجموعة محددات، يتجلى أهمها بالآتي(مد، 2013

أولاً : الطبيعة المعقدة التي تصاغ بها بعض المعايير المحاسبية مثل المعايير المرتبطة بالاستثمرات والمشتقات والأدوات المالية والمعايير المرتبطة بالقيمة العادلة عموماً. ثانياً : يكون الهدف من التقارير المحاسبية في بعض الدول هو حساب الريح الضريبي أو انتاج معلومات تساعد الخخطط القوي على اعداد البيانات القومية التي تساعد في التخطيط واتخاذ القرارات على المستوى القومي. ثالثاً : قناعة المستثمرين ومستخدي القوائم المالية الآخرين بالمعايير المحاسبية الوطنية، وقد تكون هذه القناعة في حقيتها تعود المستثمرين ومستخدي القوائم المالية على المعايير المحاسبية الوطنية إلى الدرجة التي يصعب فيها تحول اولئك المستخدمين الى قراءة قوائم

مالية أعدت بإستخدام طرائق محاسبية غير التي تعودوا عليها. رابعاً : مشكلات التزجمة، معايير المحاسبة الدولية تصدر باللغة الانجليزية ومصطلحات محاسبية انجليزية متعارف علها، وتكمن الصعوبة هنا في أن التزابم قد تصل إلى مقابل المصطلح من اللغة الوطنية ولكن المصطلح الوطني قد لا يعكس نفس المضمون المقصود في معايير المحاسبة الدولية، وبالتالي تفقد عملية الترجمة فاعليتها. ويضيف الباحثون إلى ما سبق محددات أخرى تتزكز في الافتقار لوجود نظم قانونية تنزم أو تنظم الامتثال IAS/IFRS والاحطة بتحديثاتها المستمرة، فضلاً عن محدودية فعالية الهيئات المهنية وجودة التعليم بصفة عامة والتعليم المحاسبي بصفة خاصة لتبنها، إلى جانب مشكلات نقص المتخصصين والفنيين المؤهلين والمدربين على تنفيذ تلك المعايير وارتفاع تكلة التطبيق. - 20 - n

\subsection{4 المنظات المهنية التي تُعنى بتطوير معايير المحاسبة والابلاغ الملالي الدولية} IAS/IFRS

IASC : 1 . 4 . 2. لجنة المعايير المحاسبية الدوت هذه اللجنة إلى الوجود في1973/6/29 كثمرة للاتفاقيات التي عقدت بين الجمعيات المحاسبية المهنية لعشر دول
IAS/IFRS مزايا ومحددات تطبيق معاير المحاسبة والإيلاغ الملالي الدولية 2.3 .3 لا يختلف أثنان على المزايا والمنافع المتحققة نتيجةً لتبني معايير المحاسبة والإبلاغ الملالي الدولية المنشآت ولمستخدي القوائم المالية وحتى لمهنة المحاسبة بشكل عام، ويكن إجال هذه المزايا بالآتي(ابو نصار، بلا سنة نشر : 2-3) و(طيبي ورينوبة، 2014 : 506-506) و(الشحادة والسليحات، 2015 : 42-42) : أولاً: التوافق المحاسبي : ويعني الإحتكام إلى مجموعة واحدة من المعايير في تطبيق المحاسبة وممارساتها، على أن تخظى هذه المعايير بقبول عام، ومن شأن هذا التوافق تكوين مسار شامل لإرشاد المحاسبين في إقتصاديات المنشآت ولتوجيه التنظيات والنظم المحاسبية المختلفة بين البلدان، ومن أجل إحداث الإنسجام بين النظم المحاسبية وتقليص الفروق والإختلافات والثغرات الموجودة بينها أو جعل هذه الفروق في مستوى معقول. ثانياً: القابلية للمقارنة : نظراً لتوحيد أسس وطرائق المعالجات المحاسبية فإن النتيجة المباشرة لذلك هي قابلية القوائم المالية التي أعدت على هذا النحو للمقارنة من قبل مستخدميها والمفاضلة بينها إستناداً إلى مدركات واضحة، وبالتالي ضمان سلامة إتخاذ القرارات من جانب الإعتاد على معلومات محاسبية ومالية مثماثلة وصحيحة وموثوقة. ثالثاً: تلبية متطلبات الممولين المحليين والدوليين : إذ إن المنشآت لا يككن أن تعتمد على نفسا دون غيرها، فقد تحتاج إلى مولين للتوسع في عملياتها وأنشطتها، ولا يكن لمؤسسات التمويلية أن تقوم بمنح قروض ال لمفي ضوء دراسة وافية للقوائم المالية للمنشأة التيب تختاج إلى موارد مالية، ولا يكن أن تكون هذه الدراسة الح في ضوء قوائم مالية قد أعدت وفق معايير محاسبية موحدة. رابعاً: الولوج إلى الأسواق المالية الدولية : إذ تقوم المنشآت حالياً بالمنافسة على الولوج إلى الأسواق المالية الدولية لإدراج أسهما على مستوى دولي وتداوله بسرعة كبيرة مستفيدة بذلك من وسائل الإتصال الحديثة والتحرر من القيود المثبطة للإستثار والتمويل، ولا يمكن للمنشآت تحقيق ذلك الا بالإلتزام بشروط دنيا يجب التقيد بها حتى يُسمح لها بادراج اسهما في هذه الأسواق، منها الإفصاح الملالي بناءً على

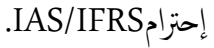

خامساً: يكفل تبني IAS/IFRS على النهو بهنة المحاسبة في الدول التي لا يوجد لديها معايير محاسبية خاصة بها، إذ تتميز IAS/IFRS بأنها وضعت بناءً على ظروف واحتياجات معظم الدول ولم تكن موبجة الى دول محددة، كما انها تمتاز بقبولها وتبنهيا مـن 
فيقصد به معايير المحاسبة الدولية وتفسيراتها ومعايير الابلاغ المالي وتفسيراتها (IFRS)

.(Ankarath et al,2010:4) (IAS,SIC,IFRS and IFRIC)

2.3.5 معايير المحاسبة والإيلاغ الملالي المولية وانعكاساتها في البيئة العراقية أدى التغير السياسي في جمهورية العراق بعد سنة2003 إلى إنتّاح واسع في البيئة الاقتصادية على العالم ليواكب التطور العالمي الحاصل في كبريات الدول، مما شتجع على تطوير وتحسين القواعد المحاسبية العراقية الصادرة قبل سنة2003 والتي عدت بمثابة الطرائق أو الوسائل التي أنشئت من أجل تطبيق المفاهيم المحاسبية الرئيسة وذلك ترك لتوفيرها إطاراً منظاً ومتاسكاً لنشر البيانات المحاسبية لنتائج أعمال الوحدة الاقتصادية ومركزها الملالي، ووضعت من قبل مجلس المعايير المحاسبية والرقابية العراقي (بصفته الجهة المسؤولة عن إصدار المعايير والقواعد المحاسبية والتدقيقية) عن طريق إصداره مجموعة من القواعد المحاسبية العراقية التي بلغ عددها(14) قاعدة، وأدلة الندقيق العراقية التي بلغ عددها(7) دليل في أثناء السنوات الممتدة من(1993 ولغاية 2017)، معتمداً في ذلك على معايير المحاسبة والتدقيق الدولية بهدف الإرتقاء بهنة المحاسبة والتدقيق ورفع المستوى المهني للقائمين بها. ومن مقارنة معايير المحاسبة والإبلاغ المالي الدولية مع القواعد المحاسبية العراقية سارية المفعول لغاية سنة2016 يتضح ان عدد معايير المحاسبة الدولية النافذة بلغ) (25) معيار، اما معايير الابلاغ المالي الدولية (IAS) فقد بلغ عددها(16) معيار، في حين أن القواعد المحاسبية العراقية الصادرة عن مجلس المعايير المحاسبية والرقابية العراقية هي (14) قاعدة محاسبية، تضم بين طياتها قاعدة محاسبية لا يوجد ما يقابلها في مسمى المعايير الدولية هي(القاعدة 12) إذ ان المتطلبات الموجودة في هذه القاعدة هي جزء من المعيار الدولي16 IAS والموسوم (الممنلكات والمصانع والمعدات). وعليه، يتضح ان هنالك احداثاً مالية واقتصادية لم ترد لها ارشادات او معالجات في أغلب القواعد المحاسبة العراقية كنها لم تتحدث لتواكب التطور السنوي الحاصل في المعاير الدولية، مما يتطلب إعادة النظر بمضمون تلك القواعد لتواكب مثيلتها

\section{وبما يحقق الهدف من إنشائها.}

2.4 منظومة التعليم وتكييف النظام المحاسبي الموحد وفق IAS/IFRS ليس من السهولة بكلن إخضاع النظام المحاسبي الموحد المعتمد في العمل المحاسبي لمتطلبات وتوجحات IAS/IFRS بين ليلة وضحاها، وذلك بسبب الموروث القديم في تطبيق المفاهيم السابقة، وصعوبة التعامل مع منشآت القطاع العام بذات أسلوب التعامل مع منشآت القطاع الخاص من ناحية مخرجات النظام المحاسبية، أضف إلى أن تطبيق
هي(أستراليا، كندا، المانيا، فرنسا، المكسيك، اليابان، هولندا، المملكة المتحدة، إيرلندا، الولايات المتحدة الأمريكية) (1 : Hanes,1980) وهي منظمة مستقلة تهدف إلى إعداد معايير يكن إستخداما من قبل الوحدات الإقتصادية لدى إعداد القوائم المالية في جميع أخحاء العالم(علاوي وآخرون، 2013 : 86) ومقرها العاصمة البريطانية، (وتسعى هذه اللجنة منذ نشأتها وحتى اعادة هيكلتها في سنة 2001) إلى صياغة ونشر المعايير المحاسبية الدولية والحث على جعلها مقبولة وقابلة للتطبيق على المستوى العالمي، والعمل على تحسين التشريعات والقوانين والمبادئ المحاسبية لعرض القوائم المالية، مع تحتيق اكبر قدر مككن من التوافق بين الممارسات المحاسبية بين الدول المختلفة بشكل يسمح باجراء المقارنة بين القوائم المالية، فضلاً عن طرح افكار محاسبية يكن تبنيها واصدارها كعايير دولية خدمة للصالح العام(القاضي, 2000 : 36). وقد اصدرت اللجنة (41) معيار محاسبي دولي (IAS) قبل ان تتم اعادة هيكتها، وتضم عضوية اللجنة جميع المنظلات المهنية المحاسبية الاعضاء في الاتحاد الدولي للمحاسبين (IFAC) والتي يبلغ عددها (143) جمعية منية ثابعة لـ(103) دولة، وفي سنة1997 انثق عن هذه اللجنة لجنة Standing Interpretation رعية سميت بد(اللجنة الائمة المتفيرات وهي الجهة الوحيدة الخولة بتفسير معايير المحاسبة الدولية (Committee - SIC) (جربوع وحلس، 2002 : 53). اما الهيئات المرتبطة بـIASC فهي مجلس لجنة المعايير المحاسبية الدولية(International accounting Standard Board- IASB)، Advisory Consultative Group المجموعة الاستشارية، المجلس الاستشاري (SIC) Standing Interpretation Council Strategy working party Committee 2. 3. 4.2 : 2. مجلس معايير المحاسبية الدولية(IASB) : هو مجلس خني لوضع المعايير الدولية ومقره في لندن ويكون مسؤولاً عن إصدار وتطوير المعايير وقد جاء نتيجة إعادة هيكة . IASC في سنة2001 تحت مسمى لتتوسع مسؤولياته ويُعنى بإلغاء وتعديل المعايير السابقة(مسعود، 2015 : 20)، فضلاً عن تفسيراتها وحتى يتم تعديلها او سحهيا واستحداث معايير جديدة تسمى بمعايير الابلاغ المالي الدولية(IFRS) وكذلك استبدال التفسيرات الصادرة عن اللجنة الدائمة للتفسيرات SIC بتفسيرات جديدة وصادرة عن International Financial لجنة جديدة هي لجنة تفسيرات الابلاغ المالي الدولية (IFRIC) Reporting Interpretation Committee 
2. الجزء الثاني : يتناول دور منظومة التعليم العالي في إعادة بناء النظام المحاسبي الموحد وفق معايير المحاسبة والإبلاغ الملالي الدولية IAS/IFRS، وتم تقسيمه على محورين :

أ. المحور الأول : ضرورة اعادة بناء النظام المحاسبي الموحد وفق IAS/IFRS، وتكون من(9) فقرات.

ب. المحور الثاني : أهمية التأهيل العلمي والكاديمي في تعزيز دور المنظومة التعليمة لبناء النظام المحاسبي الموحد وفق IAS/IFRS، وتكون من(6) فقرات. وقد كانت الإجابات على كل فقرة مكونة من (5) إجابات، إذ إن الدرجة(5) تعني موافق بشدة، والدرجة(1) تعني غير موافق بشدة، والجدول(1) في الأدنى يصور تصنيف الإجابات، وكما يأتي : الجدول(1) - 20 - تصنيف الإجابات

\begin{tabular}{|c|c|c|c|c|c|}
\hline غير موافق & غير موافق & محايد & موافق & موافق & التصنيف \\
\hline 1 & 2 & 3 & 4 & 5 & الدرجة \\
\hline
\end{tabular}

وإستكالاً لإجراءات البحث فقد قام الباحثون بإجراء مقابلات عديدة مع مجموعة من الخبراء وذوي الاختصاص للإفادة من آرائه وخبرته بموضوعة البحث.

3.1 الشروط العلمية للإستبانة

أ. صدق الإستبانة : يقصد به شموله لكل العناصر التي يجب أن تدخل في التحليل من ناحية، ووضوح فقراتها ومفرداتها من ناحية أخرى بجيث تكون مفهومة لكل من يستخدها، وقد تم التأكد من صدق الإستبانة بطريقتين : أولاً : صدق أداة الدراسة : تم عرض الإستبانة على جموعة من الخبراء والمختصين في الإختصاصات الآتية : (التدقيق، المحاسبة، العلوم المالية والمصرفية، علم الإحصاء،. . . • ) . وعدّ الباحثون الفقرات التي حصلت على موافقة الخبراء بنسبة(90\%) من آراءهم هي فقرات صحيحة ومقبولة وتماشياً مع توصية بلوم وآخرون(1983)، ففي هذا الصدد يقول "إذا حصلت نسبة الإتفاق بين المكمين(75\%) أو أكثر يمكن الشعور بالإرتياح من صدق المقياس". وبعد الأخذ بآراء الخبراء من أجل حذف بعض الفقرات غير الصالحة وإضافة وتعديل ودمج البعض الأخر بسبب التشابه بالمعنى والمضمون،

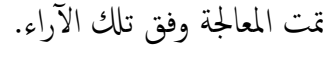

هذه المعايير يحتاج إلى بحود كبيرة بشرية ومالية، إذ سيتم قلب الإجراءات المحاسبية إلى إجراءات متوافقة مع IAS/IFRS، كذلك الحاجة إلى تأهيل وتدريب مكثفين للموارد البشرية، والنظرة السيادية إلى النظام المحاسبي الموحدوبقية النظم المالية والمحاسبية الممتمدة) بإعتباره جزء من هيبة الدولة، علاوةً على ما يككن لمسه من عوائق تتمثل في عدم مناسبة تطبيق هذه المعايير للبيئات المحلية (الجعارات، 2014 : 29)، الا إن ذلك سيؤدي إلى إنغزال مضمون النظام المحاسبي الموحد وعدم مسايرته للتجديدات والتعديلات الحاصلة وفق IAS/IFRS ما يجعل سيره يكون في شكل احادي ومنعزل عن باقي النظم المحاسبية المعتمدة في العالم، الأمر الذي سيؤدي بالنتيجة النهائية إلى التشكيك في مصداقية معلوماته المالية وعدم إجابة مخرجاته على إحتياجات الأطراف المستفيدة كافة. ولتجاوز هذه العقبة، يجد الباحثون إن بذل الجهود لتكييف النظام المحاسبي الموحد وإعادة بناءه وفق متطلبات IAS/IFRS تُعد مسؤولية يتقاسها الجميع وفي مقدمتهم الأكادييين المحترفين العاملين في المؤسسات التعليمة (كونهم أهل الإختصاص في البلد) للقيام بواجباتهم في إعداد وتخريج الكفاءات المحاسبية القادرة على الإسهام الفاعل في تحتيق مستلزمات تكييف النظام المحاسبي الموحد وفق IAS/IFRS، لذا بات من الضروري تطوير قابليات الملاكات التدريسية الختصة في حقل المحاسبة وتحسين مستواها العلمي وتخفيزها على تعميق معرفتها العامة بالتغيرات الحاصلة في هذا الحقل وفكره المحاسبي عموماً ومعاييره خصوصاً، لتقديم ضهانة فاعلة في تحقيق الأداء الأفضل ويؤكد على الدور المحاسبي في توفير معلومات ملائمة لإتخاذ القرارات الإقتصادية والمالية المختلفة. 3. المحور الثاني : الجانب التطبيتي يتضمن هذا المور عرضاً لتحليل البيانات وإختبار فرضيات البحث وإستعراض أبرز النتابُ التي تم التوصل اليها، عن طريق إعداد إستمارة إستبانة وزعت على عينة قواما(50) مفردة تم إسترداد(40) مفردة وبنسبة(80 \%)، كما تم إستخدام الأسلوب العشوائي في إختيار هذه العينة من مجتمع الدراسة الذي تكون من عدد من أساتذة SPSS الجامعات والعاملين في عدد من المؤسسات الحكومية هإستخدام بربجية لتحليل البيانات والتوصل إلى (Statistical Package for Social Sciences) النتائُ، ولقد تألفت الإستبانة الإحصائية الموزعة من جزأين، ها : 1. الجزء الأول : ويتكون من عدة أسئلة تتعلق بـ(3) متغيرات وصفية وهي(اسم

$$
\text { المؤسسة، المؤهل العلمي، التخصص الأكاديي، سنوات الخبرة). }
$$


بين كل فقرة من فقرات محاور الإستبانة والدرجة الكلية للمحور نفسه،

والجدولان(2، 3) اللاحقان يوضحان معامل الإرتباط بين كل فقرة من فقرات المجال

ثانياً : صدق المقياس

1. الإتساق الداخلي : يقصد به مدى إتساق كل فقرة من فقرات الإستبانة مع والدرجة الكلية للمجال، والذي يبين إن معاملات الإرتباط المبينة دالة عند مستوى

المجال الذي تنتي اليه هذه الفقرة، ويتم ذلك من خلال حساب معاملات الإرتباط معنوية(0. 05) وبذلك يُعد الجمال صادقاً لما وضع لقياسه. الجدول(2) : معامل الإرتباط بين فقرات المحور الأول من محاور الإستبانة

\begin{tabular}{|c|c|c|c|}
\hline $\begin{array}{c}\text { الاحتالية } \\
\text { (sig) } \\
\end{array}$ & |رباط معاط & اسئلة المحور الاول & \\
\hline 0.00 & 0.610 & يُعد تكييف النظام المحاسبي الموحد وفق IAS/IFRS ضرورة حتمية في الوقت الحاضر للإحاطة بالتطورات المتلاحقة. & 1 \\
\hline 0.00 & 0.633 & إن اعادة بناء النظام المحاسبي الموحد وفق IAS/IFRS يُعد أكثر موضوعية وأقرب للواقع. & 2 \\
\hline 0.00 & 0.555 & إن اعادة بناء النظام المحاسبي الموحد وفق يضمن إنتاج معلومات ذات جودة عالية تعطي الثقة لمستعمليها، فضلاً عن & 3 \\
\hline 0.00 & 0.440 & تسهم عملية إعادة بناء النظام المحاسبي الموحد وفق IAS/IFRS في رسم سياسة تكوين حقيقة للمحاسب وفق معايير منية صلبة. & 4 \\
\hline 0.00 & 0.651 & يساعد بناء النظام المحاسبي الموحد وفق IAS/IFRS على إمكانيـة الحصول على معلومات صادقة وقابلة للمقارنـة. & 5 \\
\hline 0.00 & 0.539 & بيئة العمل المحاسبي تتفاعل وتتاسك مقوماتها مع اعادة بناء النظام المحاسبي الموحد وفق IAS/IFRS. & 6 \\
\hline 0.00 & 0.601 & يمكن إعتبار العراق في الوقت الحالي مؤهلاً لتكييف نظامه الحماسبي الموحد وفق IAS/IFRS. & 7 \\
\hline 0.00 & 0.397 & يلزم إعادة بناء النظام المحاسبي الموحد وفقIAS/IFRS اعتمادات مالية كبيرة توازي حاجته لكفاءات تعليمية لإنجاحه. & 8 \\
\hline 0.00 & 0.638 & تعزز اعادة بناء النظام المحاسبي الموحد وفقIAS/IFRS آليات الرقابة الداخلية والخارجية كنها المفتاح الرئيس للكشف عن مكامن & 9 \\
\hline
\end{tabular}

الجدول(3) : معامل الإرتباط بين فقرات المحور الثاني من محاور الإستبانة

\begin{tabular}{|c|c|c|c|}
\hline $\begin{array}{c}\text { الاحتمثية } \\
\text { (sig) }\end{array}$ & بر معامل & \multicolumn{2}{|l|}{ اسئلة المحور الثاني } \\
\hline 0.00 & 0.712 & يمنح التأهيل العلمي والكاديي في المحاسبة وتطوراتها جرعة شافية لتعزيز بناء النظام المحاسبي الموحد وفق IAS/IFRS. & 10 \\
\hline 0.00 & 0.645 & يشكل التأهيل العلمي والكاديمي للملاكات التدريسية إستثاراً وطنياً لما يهققه من عوائد مالية تعمل على تخفيض تكلفة استقدام خبراء المناء & 11 \\
\hline 0.00 & 0.797 & 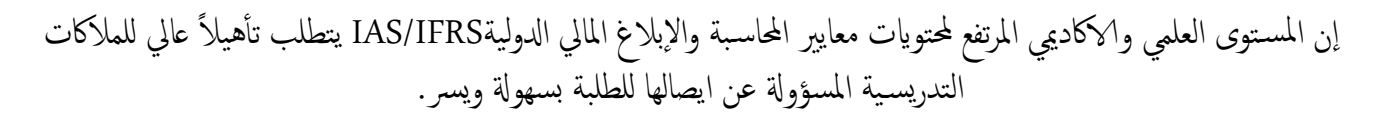 & 12 \\
\hline 0.00 & 0.464 & & 13 \\
\hline
\end{tabular}




\begin{tabular}{|c|c|c|c|}
\hline & & 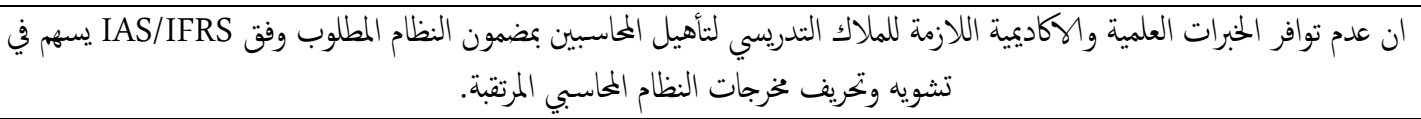 & \\
\hline 0.00 & 0.367 & إن وجود برامج تطويرية ساندة للملاكات الندريسية بشأن بناء النظام المحاسبي الموحد وفق IAS/IFRS يؤدي إلى اضفاء الأساس السليم & 14 \\
\hline 0.00 & 0.582 & ان تطوير الطرائق والمناجج النعليمية بما ينلائم وبناء النظام المحاسبي الموحد وفق IAS/IFRS يسهم في تقليل الفجوة بين النظرية والمارسة & 15 \\
\hline
\end{tabular}

2. الصدق البنائي : يُعد الصدق البنائي أحد مقاييس صدق الأداة الذي يقيس إن جميع معاملات الإرتباط في جميع مجالات الإستبانة دالة إحصائياً عند مستوى مدى تحقق الأهداف التي تسعى الإدارة للوصول الهيا، ويبين مدى إرتباط كل محور معنوية(0. 05) وبذلك تُعد محاور الإستبانة كافة صادقة لما وضعت لقياسه: من محاور البحث بالدرجة الكلية لفقرات الإستبانة، والجدول(4) في الأدنى يوضح الجدول(4) : معامل الإتباط بين درجة كل محور من محاور الإستبانة والدرجة الكلية للإستبانة

\begin{tabular}{|c|c|c|}
\hline $\begin{array}{c}\text { الاحتمالية } \\
\text { (sig) } \\
\text { (sig) }\end{array}$ & معامل & 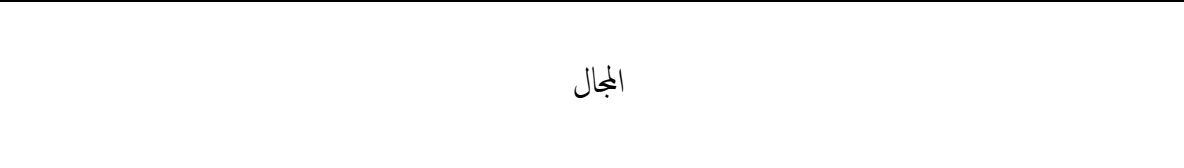 \\
\hline 0.00 & 0.828 & ضرورة اعادة بناء النظام المحاسبي الموحد وفق IAS/IFRS. \\
\hline 0.00 & 0.535 & 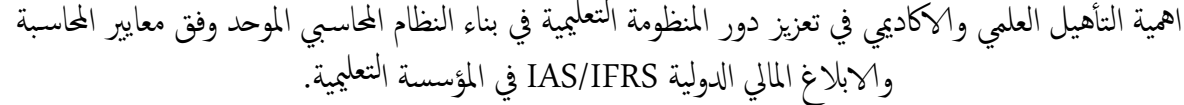 \\
\hline
\end{tabular}

أ- الثبات : يقصد به هو ان يعطي الاستبيان نفس النتائُ إذا أُعيد تطبيقه عدة مرات متتالية، وقد تم التحقق من ثبات إستبانة البحث من خلال معامل الفاكرونباخ وكانت النتائُ كما في الجدول(5) في الأدنى :

الجدول(5) : معامل الفاكرونباخ لقياس ثبات الإستبانة

\begin{tabular}{|c|c|c|c|}
\hline الصدق التي & الفاكرونباخ & 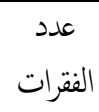 & المجال \\
\hline 0.851 & 0.725 & 9 & ضرورة اعادة بناء النظام المحاسبي الموحد وفق IAS/IFRS. \\
\hline 0.804 & 0.646 & 6 & 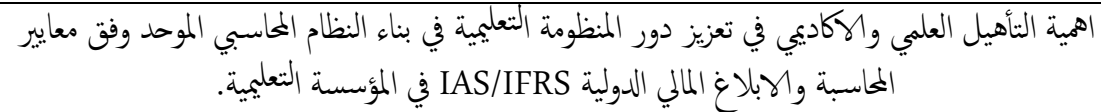 \\
\hline
\end{tabular}

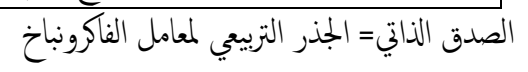

من الجدول(5) في الأعلى يتضح إن قيمة الفاكرونباخ مرتفعة للمحور الأول ونوعاً ما مرتفع ودال إحصائياً، وبذلك تكون الإستبانة في صورتها النهائية متمزة بالصدق والثبات للمحور الثاني، والتي بلغت على التوالي(025 .046) و (0.646) وهذا يعني إن الثبات مما يجعلها صالحة للتحليل والإجابة على أسئة البحث وإختبار فرضياته.

\section{2 تحليل أجوبة إستارة الإستبيان}


الجدول(6) في الأدنى يبين توزيع أفراد عينة البحث وفق متغيرات (اسم المؤسسة، أ. ت تحليل الجزء الخاص بالمتغيرات الوصفية لعينة البحث

المؤهل العلمي، التخصص الكاديمي، عدد سنوات الخدمة)، وعلى النحو الآتي :

الجدول(6) : (اسم المؤسسة، المؤهل العلمي، التخصص الكاديمي، عدد سنوات المذدمة) توزيع عينة البحث وفق متغيرات

\begin{tabular}{|c|c|c|c|c|c|c|c|c|c|c|c|c|}
\hline \multicolumn{2}{|c|}{ المجموع } & \multicolumn{2}{|c|}{ ديوان الرقابة المالية } & \multicolumn{2}{|c|}{ جامعه الهرين } & \multicolumn{2}{|c|}{ جامعة بغداد } & \multicolumn{2}{|c|}{ وزارة التعليم العالي } & \multirow[t]{2}{*}{ اسم المؤسسة } & \multirow[b]{2}{*}{ الفثات } & \multirow{2}{*}{ المتغير } \\
\hline نسبة \% & 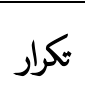 & نسبة \% & 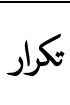 & نسبة & 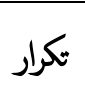 & نسبة & 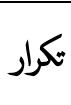 & نسبة \% & 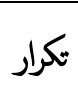 & & & \\
\hline 4. 5 & 2 & 0 & 0 & 0 & 0 & 5 & 1 & 7. 7 & 1 & \multicolumn{2}{|c|}{ 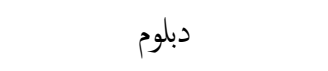 } & \multirow{5}{*}{ المؤهل العلمي } \\
\hline 15. 9 & 7 & 20 & 1 & 0 & 0 & 20 & 4 & 15. 4 & 2 & \multicolumn{2}{|c|}{ بكالوريوس } & \\
\hline 29.5 & 13 & 20 & 1 & 50 & 3 & 25 & 5 & 30.7 & 4 & \multicolumn{2}{|c|}{ ماجستير } & \\
\hline 47. 9 & 21 & 60 & 3 & 50 & 3 & 45 & 9 & 46. 2 & 6 & \multicolumn{2}{|c|}{ دكنوراه } & \\
\hline 2. 2 & 1 & 0 & 0 & 0 & 0 & 5 & 1 & 0 & 0 & \multicolumn{2}{|c|}{ اخرى } & \\
\hline 40.9 & 18 & 0 & 0 & 9.33 & 2 & 45 & 9 & 53.8 & 7 & \multicolumn{2}{|c|}{ محاسبة } & \multirow{5}{*}{ الأخصدي } \\
\hline 43. 2 & 19 & 40 & 2 & 33.3 & 2 & 50 & 10 & 38.5 & 5 & اعمال & & \\
\hline 13.6 & 6 & 60 & 3 & 6.16 & 1 & 5 & 1 & 7. 7 & 1 & لة وادارية & & \\
\hline \multirow[t]{2}{*}{2.3} & 1 & 0 & 0 & 16. 2 & 1 & 0 & 0 & 0 & 0 & \multicolumn{2}{|c|}{ اخرى } & \\
\hline & & & & & & & 3 & 7. 7 & 1 & & & \\
\hline 13.6 & 6 & 20 & 1 & 4.16 & 1 & 15 & 3 & 7. 7 & 1 & \multicolumn{2}{|c|}{ اقل من 5 سنوات } & \multirow{3}{*}{ سنوات الخبرة } \\
\hline 22.7 & 10 & 0 & 0 & 16. 2 & 1 & 30 & 6 & 23.1 & 3 & \multicolumn{2}{|c|}{ من 5 سنوات الى 10 سنة } & \\
\hline 27.4 & 12 & 20 & 1 & 8.33 & 2 & 25 & 5 & 30.7 & 4 & \multicolumn{2}{|c|}{ من 11 الى 15 سنة } & \\
\hline 36.3 & 16 & 60 & 3 & 6.33 & 2 & 30 & 6 & 38.5 & 5 & \multicolumn{2}{|c|}{ اكثر من 15 سنة } & \\
\hline
\end{tabular}

خبرة بين(5-10) سنة، وما نسبته(13، 6\%) منهم لديهم خبرة مدة(5) سنة، مما يعكس شمول شريحة عمة من ذوي المؤهلات في عينة البحث، وهكذا بالنسبة للإختصاص الأكاديي وعدد سنوات الخدمة التي توزعت على فئات متعددة.

\section{ب. تحليل الجزء الخاص بأسئلة محاور الإستبانة}

أولاً : الفرضية الأولى(إن وجود كفاءات تعليمة قادرة على تعزيز معارف المحاسبين بمضمون النظام الححاسبي الموحد المعاد بناءه وفق معايير المحاسبة والإبلاغ الملالي الدولية

، يؤدي إلى إعداد كفاءات محاسبية مؤهلة للتطبيق بأعلى مراتب الفاعلية والجودة).
من الجدول(6) في الأعلى يتضح إن الإستارات البالغ عددها(44) إستارة قد وزعت إلى(13) إستارة في وزارة التعليم العالي والبحث العلمي، و(20) إستارة في جامعة بغداد، و(6) إستارة في جامعة النهرين، و (5) إستارة في ديوان الرقابة المالية، كما يؤشر إن بحدود(50\%) من عينة البحث كان مؤهلهم العلمي(دكتوراه) وبحدود(30\%) منهم ماجستير، أما بقية النسب فقد توزعت على باقي المؤهلات، أضف إلى أن أكثر من(40\%) من عينة البحث تخصصهم الأكاديمي هو(محاسبة) و(43\%) منهم إدارة أعمال، و (\%13,6) منهم علوم مالية ومصرفية، و(\%2,3) منهم من تخصصات أخرى، كما يتضح إن ما نسبته(36\%) من عينة البحث لديهم خبرة أكثر من(15) سنة، وما سبته(27\%) منهم لديهم خبرة بين(11-15) سنة، وما نسبته(22، 7\%) منهم لديهم 
سيتم إختبار هذه الفرضية وفق تحليل المحور الأول، إذ تم إستخدام المتوسطات الحسابية والإخرافات المعيارية ومستوى الموافقة للمحور الأول ودرجة الأهمية، وكما موضح في

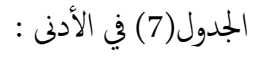

الجدول(7) : المتوسطات الحسابية والإنرافات المعيارية ومستوى الموافقة للمحور الأول ودرجة الأهمية

\begin{tabular}{|c|c|c|c|c|c|}
\hline درجة الأهمية & النتيجة & الانخراف المعياري & المتوسط & \multicolumn{2}{|l|}{ اسئلة المحور الأول } \\
\hline 2 & 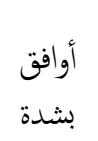 & 886.0 & 23.4 & يُعد تكييف النظام المحاسبي الموحد وفق IAS/IFRS ضرورة حتمية في الوقت الحاضر للإحاطة & 1 \\
\hline 8 & أوافق & 900.1 & 70.3 & إن اعادة بناء النظام المحاسبي الموحد وفق IAS/IFRSيُعد أكثر موضوعية وأقرب للواقع. & 2 \\
\hline 7 & أوافق & 899.0 & 73.3 & 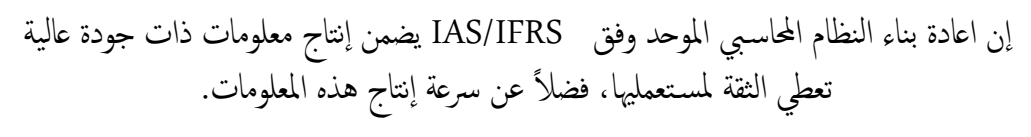 & 3 \\
\hline 6 & أوافق & 010.1 & 84.3 & تسهم عملية إعادة بناء النظام المحاسبي الموحد وفق IAS/IFRS في رسم سياسة تكوين حقيقية & 4 \\
\hline 5 & أوافق & 950.0 & 07.4 & يساعد بناء النظام المحاسبي الموحد وفق IAS/IFRSعلى إمكانيـة الحصول على معلومات صادقة & 5 \\
\hline 1 & 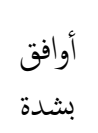 & 829.0 & 32.4 & بيئة العمل المحاسبي تتفاعل وتتخاسك مقوماتها مع اعادة بناء النظام المحاسبي الموحد & 6 \\
\hline 9 & محايد & 260.1 & 34.3 & يكن إعتبار العراق في الوقت الحالي مؤهلاً لتكييف نظامه المحاسبي الموحد وفق IAS/IFRS. & 7 \\
\hline 4 & أوافق & 300.1 & 14.4 & يلزم إعادة بناء النظام المحاسبي الموحد وفق تعلميمة لإنجاحه. اعتمادات مالية كيرة توازي حاجته لكفاءات & 8 \\
\hline 3 & أوافق & 970.0 & 18.4 & 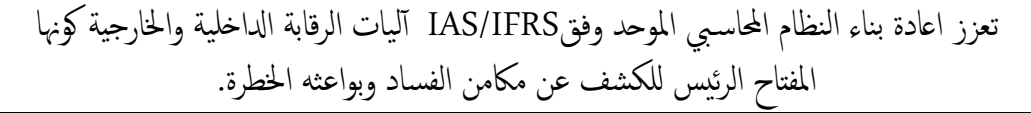 & 9 \\
\hline & أوافق & 550.0 & 95.3 & نتيجة المحور الأول & \\
\hline
\end{tabular}

معياري(26. 1). وبالنظر إلى نتيجة المحور الأول العامة فإن وبجة نظر أفراد عينة الإستبانة تتجه إلى(أوافق)، وهذا يؤدي إلى قبول الفرضية الأولى القائلة (إن وجود كفاءات تعلمية قادرة على تعزيز معارف المحاسبين بضمون النظام المحاسبي الموحد المعاد بناءه وفق معايير المحاسبة والإبلاغ الملالي الدولية يؤدي إلى إعداد كفاءات محاسبية مؤهلة للتطبيق بأعلى مراتب الفاعلية والجودة).
من الجدول(7) في الأعلى، نجد إن المحور الأول قد حقق وسطاً حسابياً عاماً بلغ(95. 3) وبإخراف معياري(550. 0)، اما على مستوى الفقرات فقد تراوحت قيم الوسط الحسابي بين(32. 4) للفقرة السادسة( بيئة العمل المحاسبي تتفاعل وتتاسك مقوماتها مع اعادة بناء النظام المحاسبي الموحد وفق IAS/IFRS ) وبإنحراف معياري(829. 0)، وبين أقل قيمة وسط حسابي حقتتها الفقرة السابعة( يمكن إعتبار العراق في الوقت الحالي مؤهلاً لنكييف نظامه المحاسبي الموحد وفق IAS/IFRS)، إذ بلغ(34. 3) وبإنراف 
(sig ) فإن متوسط آراء الأفراد حول المحور الثاني لا يختلف جوهرياً عن موافق بدرجة متوسط وهي(3)، اما إذا كانت( (0,05) (sig)، فإن متوسط آراء الأفراد للمحور الثاني يختلف جوهرياً عن درجة الموافقة المتوسطة، وفي هذه الحالة يككن تحديد ما إذا كان متوسط الإجابة يزيد أو ينقص بصورة جوهرية عن درجة الموافقة المتوسطة، وذلك من خلال قيمة الإختبار فإذا كانت موجبة فإن المتوسط الحسابي للإجابة يزيد عن درجة الموافقة المتوسطة، والعكس بالعكس، وكما موضح في الجدول(8) في الأدنى : الجدول(8) : المتوسط الحسابي وقيمة الإحتال(sig) لكل فقرة من فقرات المحور الثاني

\begin{tabular}{|c|c|c|c|c|c|}
\hline التزيب & $\begin{array}{l}\text { القيمة الاحتمالية } \\
\text { (sig) }\end{array}$ & قيمة الاختبار & المتوسط المسابي & الفقرة & \\
\hline 2 & 0.00 & 10.09 & 4. 30 & 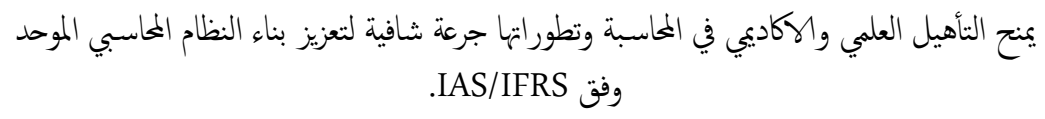 & 10 \\
\hline 6 & 0.00 & 4. 357 & 3.73 & 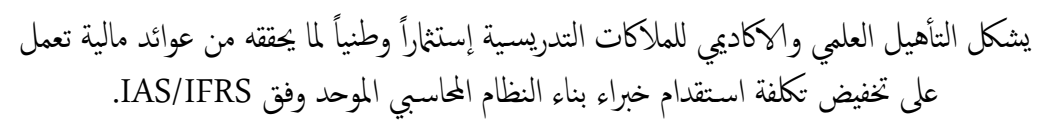 & 11 \\
\hline 4 & 0.00 & 7. 443 & 4. 16 & 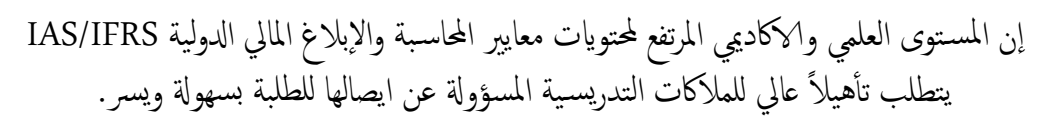 & 12 \\
\hline 5 & 0.00 & 8. 106 & 4. 14 & 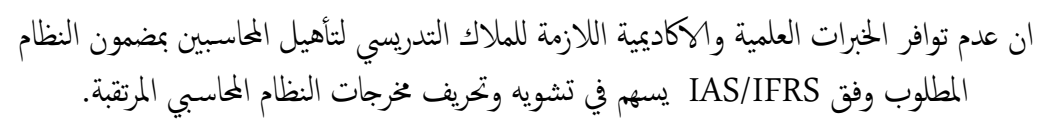 & 13 \\
\hline 1 & 0.00 & 11.816 & 4. 32 & 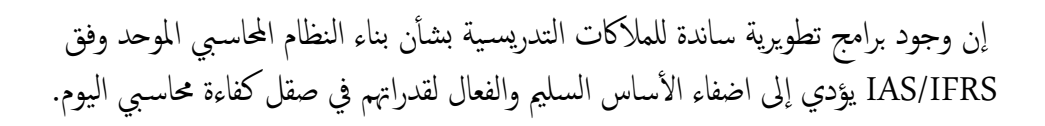 & 14 \\
\hline 3 & 0.00 & 9. 791 & 4. 23 & 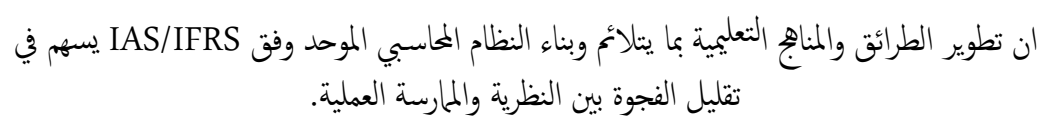 & 15 \\
\hline & 0.00 & 13. 922 & 4. 15 & جميع فقرات المحور معاً & \\
\hline
\end{tabular}

المتوسط الحسابي دال إحصائياً عند مستوى دلالة $(0,05)$

الإختبار(11.816) وإن القيمة الإحتالية(sig = 00 لذلك تُعد هذه الفقرة دالة إحصائياً عند مستوى دلالة (0,05) ويدل ذلك على أن متوسط درجة الإستجابة لهذه الفقرة قد زاد عن درجة الموافقة المتوسطة وهي(3) ويعني ذلك إن هنالك موافقة بدرجة كيرة جداً من قبل أفراد العينة على هذه الفقرة.

ثانياً: الفرضية الثانية(يوجد دور ذو دلالة إحصائية عند مستوى معنوية(0. 05) لوجود مؤهلات لأساتذة الجامعات وتطوير الخخرجات المحاسبية في مجال تطبيق النظام المحاسبي الموحد المعاد بناءه وفق معايير المحاسبة والإبلاغ الملالي الدولية لـ2AS/IFRS). لإختبار هذه الفرضية سيتم الإعتاد على إختبار(T-TEST) لمعرفة ما إذا كان متوسط درجة الإستجابة قد وصل إلى درجة الموافقة المتوسطة وهي(3) أم زادت أو قلت عن ذلك، وسيتم التأكد من دلالة المتوسط لكل فقرة من فقرات المحور الثاني، فإذا كانت( (0,05)

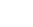

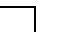


ذلك قيمة الوسط الحسابي للإجابات التي بلغت(32. 4) وبإخراف معياري(829. 0)، كما أبمع أغلب المستجيبين على أن اقليم كوردستان والعراق في الوقت الحالي لا يُعد مؤهلاً لنكييف نظامه المحاسبي الموحد وفق IAS/IFRS، ويعزّز ذلك قيمة الوسط

$$
\text { الحسابي البالغة (34. 3) وبإنحراف معياري(26. 1). }
$$

ج. بينت نتائُ التحليل الإحصائي اتفاق المستجييين عموماً على أن وجود برامج IAS/IFRS تطويرية ساندة للملاكات التدريسية بشأن بناء النظام المحاسبي الموحد وفق تيق يؤدي إلى اضفاء الأساس السليم والفعال لقدراتهم في صقل كفاءة محاسبي اليوم، ويعزز

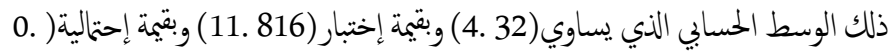
sig = 00 )، فضلاً عن أن التأهيل العلمي والكاديي للملاكات التدريسية يشكل إستثماراً وطنياً لما يحققه من عوائد مالية تعمل على تخفيض تكلفة استقدام خبراء بناء النظام المحاسبي الموحد وفق IAS/IFRS وبوسط حسابي يساوي(33 .3) وبقيمة إختبار (457 ) وبتيمة إحتالية(sig = 00. 00.

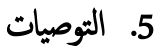
أ. ضرورة إستمرار بناء المهارات والمعارف اللازمة لأساتذة المحاسبة في الجامعات كافة لضمان التعامل مع التحديثات في هذا المجال والذي ينعكس بالنتيجة ايجاباً على جودة

$$
\text { وكفاءة المخرجات المحاسبية. }
$$

ب. ضرورة إهتام الجهات المسؤولة عن الارتقاء بهنة المحاسبة والتدقيق ببرامج الندريب وورش العمل التي تُعنى برفع فاعلية وكفاءة القائمين على نشر العلم المحاسبي بين صفوف الطلبة في الجانبين(الأكاديي والمهني)، وبما ينسجم مع متطلبات المعطيات الجديدة

$$
\text { لنكييف النظام المحاسبي الموحد وفق IAS/IFRS. }
$$

ت. تشكيل لجنة تضم في عضويتها جحات مختلفة مثثلة عن(نقابة المحاسبين والمدققين كوردستان، الجمعية العراقية للمحاسبين القانونيين ، مجلس هنة مراقبة وتدقيق الحسابات، ديوان الرقابة المالية ) وبحات مثثلة للقطاع الخاص(اساتذة جامعات أهلية) فضلاً عن أساتذة الجامعات الحكومية)) تُكلف بدراسة معمقة لـ IAS/IFRS وإمكانية تكييف النظام المحاسبي الموحد وفقها على أن ترفع نتأُج هذه الدراسة إلى مجلس المعايير المحاسبية والرقابية للبت فها وتحديد مراحل ووقت التنفيذ ومنابعة النتائُ، مع الاستعانة بتجارب الدول التي اثبتت نجاعتها في اعادة بناء نظمها المحاسبية وفق IAS/IFRS والحلول التي وضعتها لتذليل أي معوقات وابهتها أثناء التطبيق.
ب. المتوسط الحسابي للفترة(11/ يشكل التأهيل العلمي والكاديي للملاكات التدريسية إستثماراً وطنياً لما يجققه من عوائد مالية تعمل على تخفيض تكلة استقدام

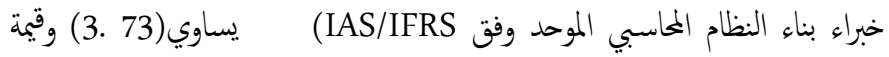
الإختبار(457 .45 وإن القيمة الإحتالية(sig = ل لذلك تُعد هذه الفقرة دالة إحصائياً عند مستوى دلالة (0,05) ويدل ذلك على أن متوسط درجة الإستجابة لهذه الفترة قد زاد عن درجة الموافقة المتوسطة وهي(3) ويعني ذلك إن هنالك موافقة بدرجة كيرة جداً من قبل أفراد العينة على هذه الفقرة. ت. بشكل عام فإن المتوسط الحسابي(45 .4) وقيمة الإختبار(922 .13) والتيمة الإحتالية(sig = 0 0 الذلك يُعد المحور الثاني دال إحصائياً عند مستوى دلالة (0,05) ويدل ذلك على أن متوسط درجة الإستجابة لهذه الفقرة قد زاد عن درجة الموافقة المتوسطة وهي(3) ويعني ذلك إن هنالك موافقة بدرجة كبيرة جداً من قبل أفراد العينة على هذه الفقرة. وبالتالي يتم قبول الفرضية الثانية القائلة(يوجد دور ذو دلالة إحصائية عند مستوى معنوية(0. 05) لوجود مؤهلات لأساتذة الجامعات وتطوير المخرجات المحاسبية في مجال تطبيق النظام المحاسبي الموحد المعاد بناءه وفق معايير المحاسبة والإبلاغ المالي الدولية IAS/IFRS). 4. المحور الرابع : الإستناجات والتوصيات

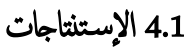

أ. يُعد التوجه نحو اعادة بناء النظام المحاسبي الموحد وفقIAS/IFRS احد الوسائل المطلوبة في الوقت الراهن لتضييق جفوة الاختلاف بين القواعد والمارسات المحاسبية، وتحسين قابلية القوائم المالية للمقارنة، فضلاً عن جعلها أكثر قرباً وفهاً لمتطلبات السوق العالمية، مع الإفادة منها في إيجاد حلول للمشكلات المحاسبية المتزايدة. ب. عدم إمتلاك معظم أساتذة الجامعات لفلسفة تطوير وتعزيز معارفهم الذاتية مما يؤثر بالنتيجة سلباً على كفاءة المخرجات المحاسبية القادرة على مواجهة متطلبات العمل وتحقيق الفائدة المرجوة بأعلى مراتب الجودة. ت. أفرزت نتائج البحث إن جميع معاملات الإرتباط في جميع مجالات الإستبانة دالة إحصائياً عند مستوى معنوية(0. 05) وبذلك تُعد محاور الإستبانة كافة صادقة لما وضعت لقياسه. ث. أظهرت ننائُ التحليل الإحصائي تأييد المستجيبين بشأن إن بيئة العمل المحاسبي تتفاعل وتتاسك مقوماتها مع اعادة بناء النظام المحاسبي الموحد وفق IAS/IFRS، ويعزّز 
16. طيبي، حمزة، رينوبة، لخضر، (2014)، "إعداد المعلومات المالية والمحاسبية وفق المعايير الدولية

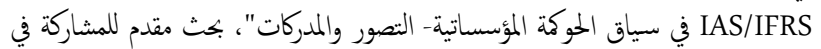

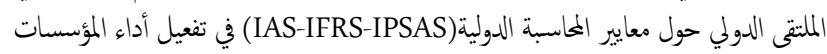

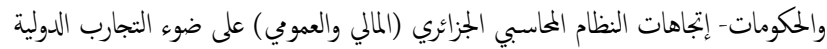

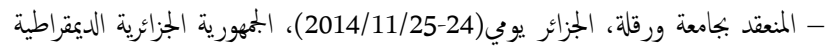
الشعبية.

17. عارف، كاظم فرج، (2015)، "معوقات تطبيق إدارة الجودة الشاملة في جامعة السليانية التقنية

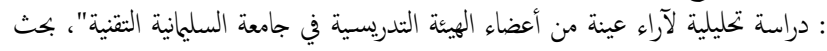

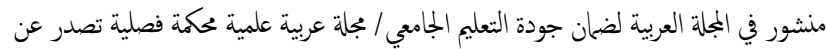

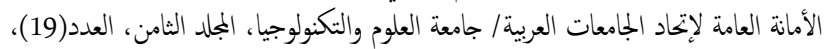
صنعاء- المههورية اليمنية.

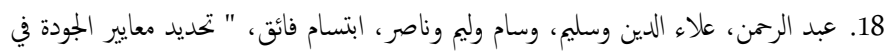

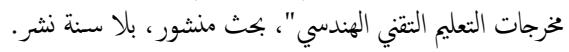

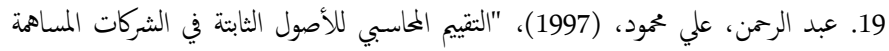

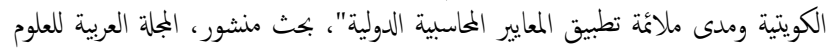

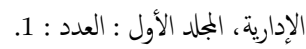

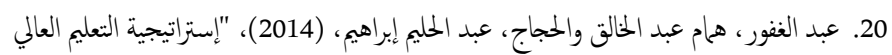

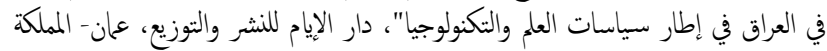
الأرنية الهاشمية.

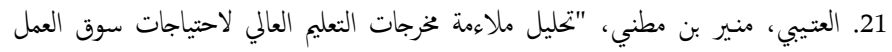

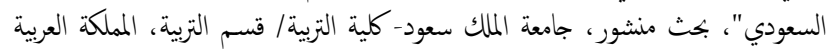

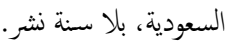

22. علاوي، محمد حويش وعمر، صبيحة صالح ومال الله، ايمان عبد المنعم، (2013)، "النظام المبام

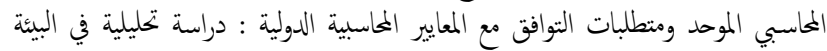

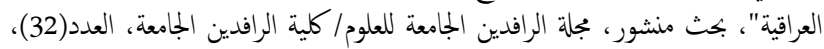
بغداد- جمهورية العراق. 23. عنبر ، أسيل جبار والعمّار ، حنان عبدالله حسن، (2015)، "مدى تأثير كفاءة مدخلات

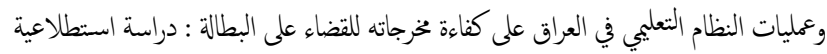

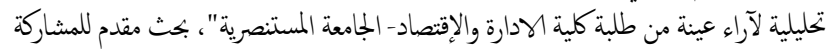

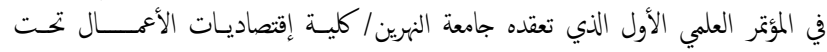

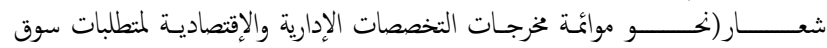

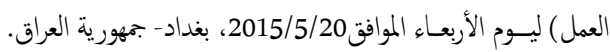

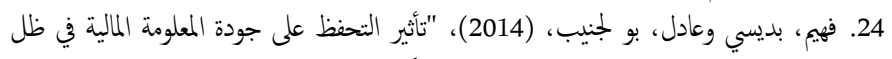

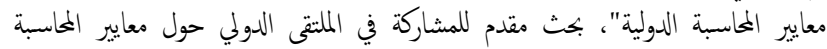

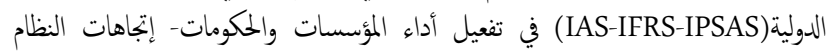

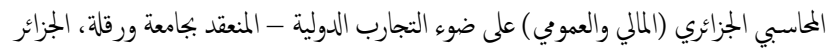
يوي(2014/11/25-24)، الجمهورية الجزائرية الديمقراطية الشعبية.

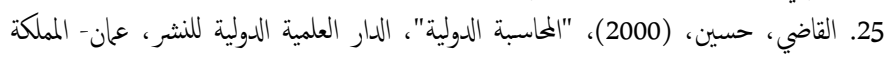
الأردنية الهاثمية.

26. كتوش، عاشور ، (2014)، "النظام المحاسبي المالي بين اتجاهاته ومتطلبات تطبيقه في ظل المعايير

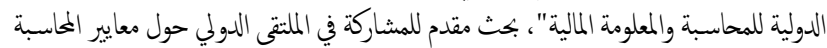

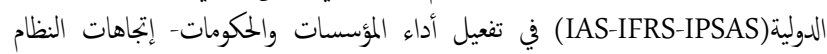

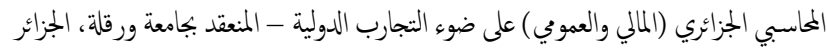
يوي(2014/11/25-24)، المجهورية الجزائرية الديمقراطية الشعبية.

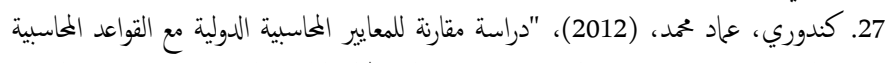

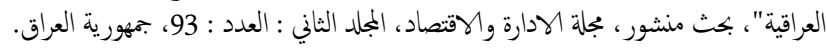

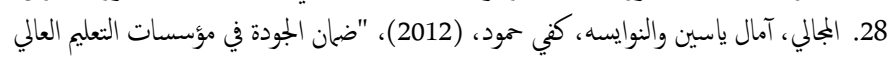

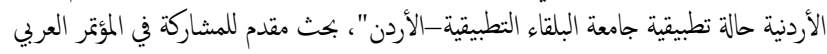
الدولي الثاني لضمان جودة التعليم العالي.
ث. فنح المجال أمام الباحثن والدارسين للقيام بإعداد بحوث ودراسات متخصصة في إعادة بناء النظام المحاسبي الموحد وفقIAS/IFR وبما يكفل الإسهام في إقتراح بعض الحلول للمشكلات التي تعترض عملية إعادة البناء.

\section{قائمة المصادر}

المصادر العربية

1. أبو نصار ، "تنيني معايير المحاسبة والإبلاغ المالمي الدولية بين النظرية والتطبيق : التجربة الأردنية"،

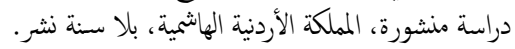

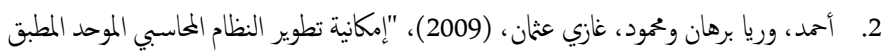

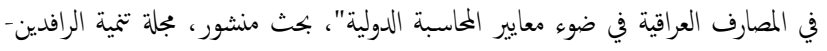

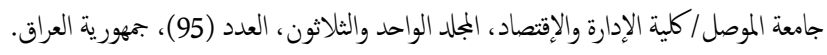

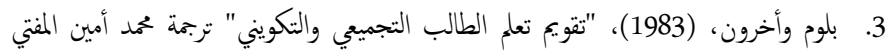
وأخرون، دار ماكجر و هيل للنشر. 4. جربوع، يوسف محمود وحلس، سالم عبد الله، (2002)، "الماسبة الدولية مع التطبيق العملي لمعايير المحاسبة الدولية"، مؤسسة الوراق للنشر والتوزيع, عمان- المملكة الأردنية الهاشمية.

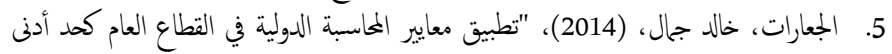

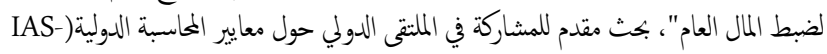
(IFRS-IPSAS

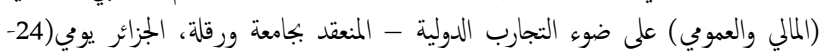

$$
\begin{aligned}
& \text { 2014/11/25)، الجمهورية الجزائرية الديمقراطية الشعبية. } \\
& \text { 6. . جمهورية العراق، (1985)، "النظام المحاسبي الموحد". } \\
& \text { 7. }
\end{aligned}
$$

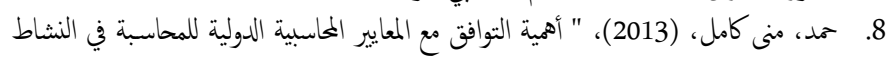

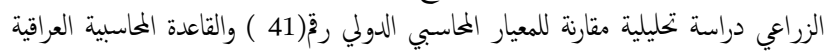

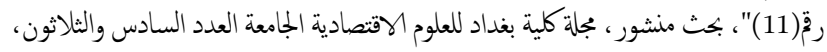

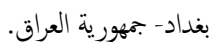

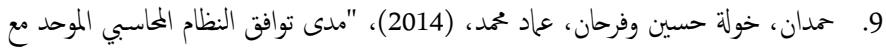

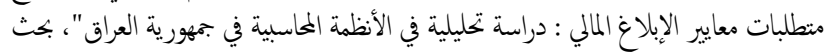

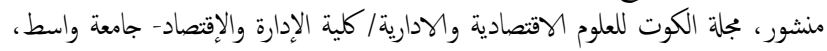

$$
\text { العدد(13)، واسط- جمهورية العراق. }
$$

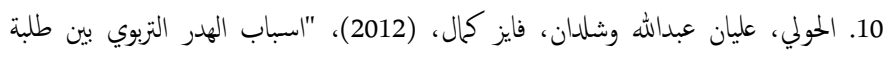

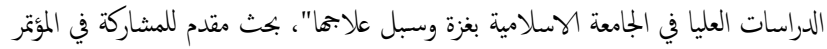
العربي الدولي الثاني لضمان جودة التعليم العالي.

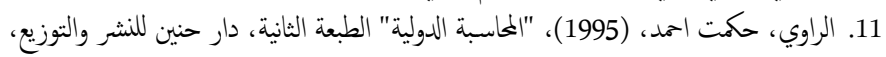
عان- المملكة الأردنية الهاشمية.

12. رقاد، صليحة، (2014)، "تطبيق نظام ضان الجودة في مؤسسات التعليم العالي الجزائرية/ آفاقه الماته

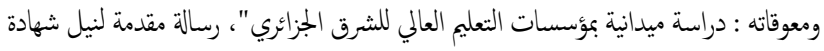

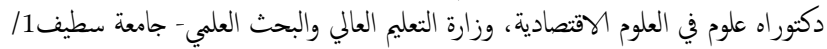

كلية العلوم الاقتصادية والتجارية وعلوم التسيير، الجمهورية الجزائرية الديمقراطية الشعبية.

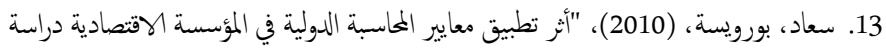

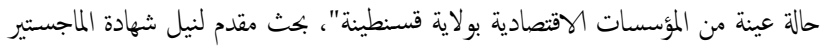

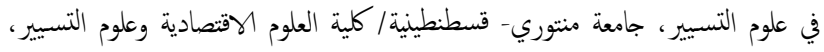
المجهورية الجزائرية الديمقراطية الشعبية.

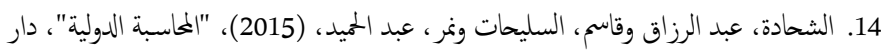
وائل للنشر، عمان- المملكة الأردنية الهاشمية.

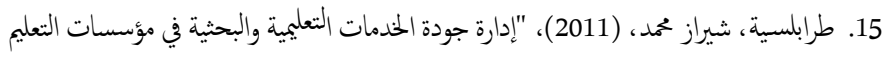
العالي"، ط1، دار الإعصار العلمي للنشر والتوزيع، عمان- المملكة الأردنية الهاثمية. 


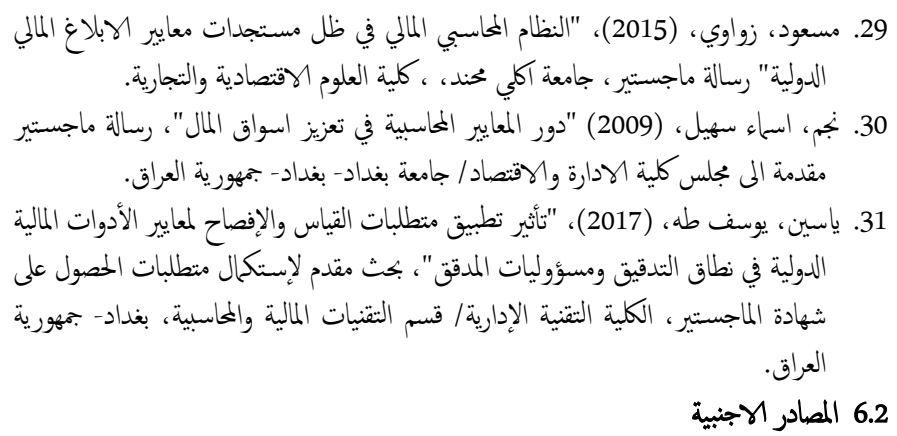

1- Ankarath, Nandakumar, Mehta, Kalprsh and Alkafaji, Yass, (2010), "Understanding IFRS fundementals", John wiley \& Sons Inc..

2- Antill, Nick. and Lee, Kenneth, (2008), "Company valuation under IFRS" 2nd edition, Harriman house Ltd.

3- Hanes, Donald J. , (1980), "The international Accounting Standards Committee Recant Develop cat and Current problems", the international journal of Accounting edition and research, Urbana Champing, Vol. 16, No. 1.

4- Rogero,Hall, (1998) "Charateristics of High Quality Accountuing Standards" Accounting Horizons, Vol. 12,no. 2,June.

6.3

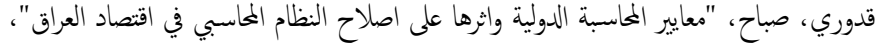

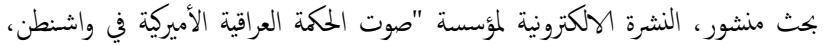
2017، على الموقع الاككتروني :

49-54-02-11-04-2014-870http : //www. iawvw. com/research-studies/ 